University of Rhode Island

DigitalCommons@URI

Open Access Dissertations

2017

\title{
A Description of Approachable Nurses: The Voice of the Hospitalized Child
}

Bethany J. Coia

University of Rhode Island, bcoia@ric.edu

Follow this and additional works at: https://digitalcommons.uri.edu/oa_diss

\section{Recommended Citation}

Coia, Bethany J., "A Description of Approachable Nurses: The Voice of the Hospitalized Child" (2017). Open Access Dissertations. Paper 643.

https://digitalcommons.uri.edu/oa_diss/643

This Dissertation is brought to you for free and open access by DigitalCommons@URI. It has been accepted for inclusion in Open Access Dissertations by an authorized administrator of DigitalCommons@URI. For more information, please contact digitalcommons-group@uri.edu. 
A DESCRIPTION OF APPROACHABLE NURSES:

THE VOICE OF THE HOSPITALIZED CHILD

\section{BY}

BETHANY J. COIA

A DISSERTATION SUBMITTED IN PARTIAL FULFILLMENT OF THE REQUIREMENTS FOR THE DEGREE OF

DOCTOR OF PHILOSOPHY

IN

NURSING

UNIVERSITY OF RHODE ISLAND

2017 


\title{
DOCTOR OF PHILOSOPHY DISSERTATION
}

\author{
$\mathrm{OF}$
}

BETHANY J. COIA

\section{APPROVED:}

Dissertation Committee:

Major Professor: $\quad$ Donna Schwartz-Barcott
Ginette Ferszt
Rachel DiCioccio
Nasser H. Zawia
DEAN OF THE GRADUATE SCHOOL

UNIVERSITY OF RHODE ISLAND

2017 


\begin{abstract}
In 1989, international attention was drawn to the rights of children in a treaty signed by representatives of 190 nations at The Convention on the Rights of the Child. A major emphasis of the treaty was on the rights of all children to be heard across a wide range of contexts. Numerous researchers have been funded to describe and enhance the voice of the child in many settings, albeit few have focused on the child in a hospital setting. Nurse researchers who have begun to investigate the experience of children during hospitalization have identified some of the positive and negative impacts of differing patterns of communication. A number of potential characteristics of an approachable nurse were hinted at in these studies, although none explored the concept of approachability among pediatric nurses. In this study the voices of school age children were sought on their experiences with and perceptions of approachable pediatric nurses.
\end{abstract}

An exploratory, qualitative, descriptive research design, including semistructured interviews with 7 school age children (6-12 years old), in a pediatric oncology service was used to gain the children's general perceptions of nurses who they think and feel are approachable and descriptions of the characteristics, behaviors and impact of these nurses. The setting was an urban children's hospital in Southern New England wherein school age children with a cancer diagnosis were interviewed both inpatient and from the outpatient oncology clinic within the same facility. Qualitative content analysis was used to analyze the data. All the children had experience with more than one approachable nurse. Common terms used by children to describe the characteristics and behaviors of an approachable nurse included nurses 
who were funny, took time to listen and talk, were nice, smiled and were happy, made them feel welcome and told them what was going to happen before the occurrence of an intervention. The impact of the approachable nurse was identified as relieving anxiety and fear, along with making these children feel welcome and relaxed while in the hospital. When needing to return to the hospital, the children were less worried because of the behaviors of these approachable nurses. Many described these approachable behaviors as making them feel at home while in the hospital.

Implications of this research aim to provoke future work on concept definition, measurement and theory development, with future consideration being given to symbolic interaction theory. Upcoming educational programs for pediatrics may use this as a point of discussion and nursing administrators may consider this as part of orientation, evaluation and peer review. Clinical practice can be advanced by increased attention to interactions between the nurse and child in the hospital setting. 


\section{Acknowledgements}

To my major professor, Donna Schwartz-Barcott, I am deeply grateful for your unfailing support. You are truly a great thinker. I have never met anyone with your ability to stimulate the mind and bring forth ideas that are beyond what is thought to be imaginable. You have been the one guiding me through this journey, one step at a time, pushing me to my fullest potential. Thank you for your amazing wisdom and for encouraging me to create a piece of work that I could be proud of. Knowing that pediatrics was not your specialty, your support and enthusiasm about my topic provided me with the notion that my work was important and necessary. It has been an absolute privilege to work with you. I will miss our great discussions and meetings and be forever grateful to you.

To my second and so very important, Ginette Ferszt, you have been extraordinarily supportive in ways you may never know. Thank you for your listening ear, encouragement and uplifting words of wisdom. Knowing you have been there for me has made this journey bearable. Rachel DiCioccio, you have been an amazing bright light with outside insight that brought a unique and wonderful perspective to my work. I appreciate your sincerity, support and willingness to engage in my work even when you were supposed to be on vacation. Geoff Leatham, thank you for your excitement and desire to be part of my team. Your input has been so meaningful and your presence so important.

It is with great sincerity that I thank Fran Pingitore for her willingness, without hesitation to be my necessary link to perform research at the children's hospital of my choice. Your constant voice of support and guidance throughout the data collection 
piece has been a driving force in my success. Barbara Bancroft, thank you for leading me through the tedious process of obtaining Institutional Review Board approval. You never failed to be there when I needed you and you were dedicated to the success of my project.

To my colleagues at Rhode Island College, Claire, Nicole, Donna and Yolande, thank you for all of your support, your listening ears when I needed to either share frustration or request guidance. You have been there for me from the beginning and your encouragement has meant more to me than you can imagine. Jane, I cannot tell you how much your support has meant to me during this journey. I am forever grateful for the unending expressions of encouragement from my friends and colleagues at Rhode Island College.

To my children, Michael, Rachel and Sarah, you have been my rock and my reason for waking up every day and pursuing this dream. This has been quite a journey for all of us in ways no one outside our home could ever imagine. Every day, knowing that the 3 of you have been there for me, believing in me and encouraging me not to give up has made this dream come true. In my lowest moments, being able to see your faces, talk to you and hug you, has given me the courage to keep going. It is my hope that I have also taught you by example, that dreams can come true and that everything and anything is possible with hard work, perseverance and God. I love you all and I look forward to more time spent together in our future. Thank you for your unconditional support and love.

Family also means giving thanks to my mother. Mom, without you, I don't know where I would be. Thank you for your relentless support and love. No matter 
when, no matter what, you have been there for me and for that I have been blessed and am so grateful. Thank you for all the dinners cooked, laundry folded, rides for my children and prayers so that I could accomplish this work. To my sisters, Maria and Lisa, thank you for your unending love, support and presence through this journey. Your words of encouragement have been the fuel for my dreams.

To all of the children who participated in this study, I am forever grateful. Time spent talking to you and your families has instilled in my heart a greater passion than I ever believed possible to make a positive difference in the lives of all children, especially those hospitalized. Always close to my heart are the pediatric oncology patients. Lessons I have learned from your words and our conversations are some of the most profound and meaningful moments of my life. It has truly been a humbling experience to be in your presence and it is all of you that have given purpose to my work. 


\section{Dedication}

It is with my entire heart and soul that I dedicate this doctoral work to my deceased father, Dr. Domenico Cortellessa Petronio. My father was a first generation college graduate. His parents, from Italy, instilled in him the need to work hard and become educated. Proudly, my father not only went to college but graduated from the University of Bologna Medical School in Italy and practiced as a prominent pediatrician in Rhode Island for many years. As a child, he instilled in me and my sisters that nothing was impossible with effort, desire and hard work. He was my example, a selfless man; he put his family, God and the care of children always before his needs. Teaching me to "be the best you can be at whatever you do in life," and supporting me every step of the way. He never counted the hours of work in a day or in a week but put himself before the needs of others. My father was a pediatrician and my mother a pediatric nurse. In choosing the path of pediatric nursing, both of my parents could not have been more proud. Privileged to have worked with my father after graduating from nursing school, I was able to see first-hand his undeniable love for children and passion to keep them well. Dad, it is with deep regret that you are not with me as I complete this work and defend my dissertation but it is my prayer that you are looking down from heaven at me, smiling and proud of your daughter. This journey has certainly been challenging in ways I never expected but it is without a doubt that you have been there with me every step of the way. Thank you for all of the incredibly invaluable lessons you taught me for without you, none of this would have been possible. I always knew you believed in me and could count on you as my

loyal and faithful advocate. You gave me the foundation to build my life upon and the 
desire to be a champion for children as you were. This doctoral work is dedicated to you Dad.

You have been and always will be an inspiration in my life.

I miss you, love you and will forever hold you close to my heart.

God Bless You Dad! 


\section{Preface}

In my mind, there is beauty in every child. I have a passion for pediatric nursing. My day is complete if I can make the life of a child happier and more fulfilled.

When I was old enough, I began to babysit. There was nothing I would not do to protect and make children happy. My mother was a pediatric nurse and my father a pediatrician, I was surrounded by parents with a passion for children. Choosing to become a nurse was always a dream of mine. Entering nursing school at the University of Vermont was an exciting time in my life. Throughout my clinical rotations in nursing school, my goals were confirmed to pursue my dream and desire for pediatrics. This was the first time I began to realize that many people, particularly health care providers, do not see or understand the need for effective communication with children in a health care setting. As a student, I was placed with the nurse I was working with in a treatment room with a child being diagnosed with leukemia. The nurse and physicians present were very intelligent and technically capable of completing the skill of this horrific bone marrow aspiration. The child was not sedated and no one seemed to address the fears of the screaming boy lying on the table. As I spoke to the child, I thought "Why is no one else talking to this child?" At that instant, I began talking to him, looking right into his eyes, telling him that he would be okay and letting him know what was happening in words and with analogies he could understand. As I walked out of the room with the team, the attending physician looked at me and said "wow, you did a great job talking to that kid!" My heart was still racing as I said "thanks." This was the first clinical experience that led 
me to develop an interest in communication between children and nurses and other health care providers.

As my career in pediatrics developed, I encountered many different communication mishaps. In my first place of employment, I worked at Boston Children's Hospital. Again, I watched as highly intelligent nurses and physicians ordered treatments and procedures and operated, but few could effectively communicate with children. Following jobs ensued at Hasbro Children's Hospital and Loyola Medical Center in Illinois. I worked with children of all ages and illnesses. My particular area of interest was pediatric oncology. It was here that I listened to the fears, the hopes and the dreams of children, even those terminally ill. I got on the floor and played with small children and sat and listened and cried with adolescents in the hospital and in the pediatric clinics. By showing these children that I truly cared about their well-being and meeting their needs in a kind and compassionate manner, a trusting, therapeutic relationship developed. I continued on to health care in the home and held and cared for children with rare diseases. In Merrick, NY, I cared for a child, 4 years of age with recessive dystrophic epidermolysis bullosa. This little girl suffered daily, with dressing changes that required methadone with puppet and play therapy by her grandparents just to tolerate necessary care. She lacked necessary collagen and therefore lived with skin that sloughed off comparative to a child with approximately $90 \%$ body surface area burns. Healing and cure did not exist. Trust with this child was extremely difficult to obtain. After a few weeks of care, she allowed me to hold her, a huge endeavor. Her mother sat and looked at me and said "you can never leave." 
Currently, working as a pediatric faculty member, I take undergraduate nursing students to a children's hospital for clinical learning. Many of the students, over the past 8 years of teaching, have looked at me and said "I am afraid to talk to kids," and "I don't know what to say to them and how to act." I find many standing outside the room of the child they are assigned to and when I ask them what is wrong, they usually respond that they just don't know how to behave with children and are scared to enter the room. Working throughout my career as a pediatric nurse for the past 28 years has brought me to realize that pediatric nurses must "connect" and communicate with children in an effective, developmentally appropriate, compassionate manner to develop a trusting therapeutic relationship. My goal is to conduct research that will provide nurses with the knowledge and skills required to be able to communicate effectively with children in a health care setting and the ability to respond to children in ways that are comforting and compassionate. 


\section{Table of Contents}

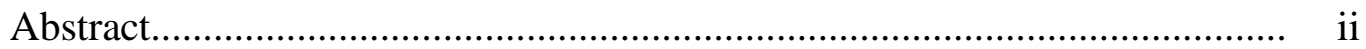

Acknowledgements..................................................................... iv

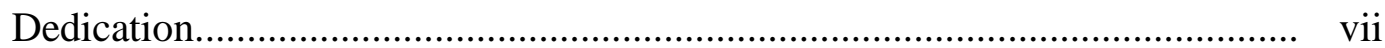

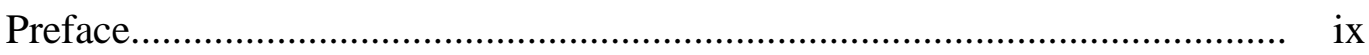

Table of Contents......................................................................... xii

Chapter 1: Introduction .................................................................... 1

Significance of Study for the Discipline of Nursing......................... 4

Chapter 2: Literature Review............................................................... 9

Rights of the Child................................................................... 9

Negative Effects of Poor Communication.................................... 12

Positive Effects of Therapeutic Communication.............................. 13

Concept Analysis of the Approachability of the Pediatric Nurse......... 15

Potential Characteristics of an Approachable Nurse......................... 17

Phase II: Fieldwork................................................................. 20

“Sophia Princess of Power." ............................................. 21

“Crazy Ken." ................................................................ 23

"Lydia." ........................................................................ 24

Phase III: Final Analytical Phase................................................... 27

Chapter 3: Methods......................................................................... 30

Research Design............................................................... 30

Setting and Participants......................................................... 31

Gaining Entry ..................................................................... 34 
Participants ......................................................................... 34

Recruitment ................................................................... 36

Data Collection........................................................................... 38

Data Analysis .................................................................... 43

Ethical Considerations................................................................. 47

Trustworthiness....................................................................... 49

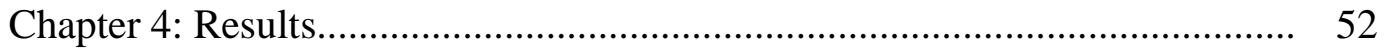

Individual Portraits.................................................................. 52

"Santa Claus." .................................................................... 52

"Wolverine." ...................................................................... 54

"Dan." ........................................................................ 56

"Jayson." ...................................................................... 58

"Vladimir." ........................................................................ 60

"Carley." .................................................................. 62

"Hobbs." ......................................................................... 64

Perceptions of Approachable Nurses............................................ 67

Nurses are "nice" ......................................................... 69

Nurses are "smiling and happy" ........................................ 71

Nurses are playful........................................................... 73

Nurses "talk and listen"................................................... 74

Nurses are creative and competent.................................... 75

Impact of Approachability....................................................... 77

Knowledge/Knowing .................................................... 77

Talking and listening................................................... 78 
Fun and humor........................................................... 80

Creativity and competence................................................ 81

Attire ..................................................................... 82

Discussion......................................................................... 83

Chapter 5: Summary, Conclusions and Implications................................. 89

Conclusions........................................................................ 94

Limitations......................................................................... 96

Implications.................................................................... 98

Future research........................................................ 98

Theory development...................................................... 101

Education.................................................................. 103

Nursing administration...................................................... 104

Clinical practice............................................................ 105

Appendix A: Lifespan IRB expedited review/approval letter....................... 107

Appendix B: IAA agreement between Lifespan and URI........................... 111

Appendix C: Lifespan approved recruitment flyer................................... 112

Appendix D: Lifespan approved Consent to Contact.................................. 113

Appendix E: Lifespan approved Parental Consent.................................... 114

Appendix F: Lifespan approved Child Assent........................................ 120

Appendix G: Lifespan approved Interview Guide..................................... 122

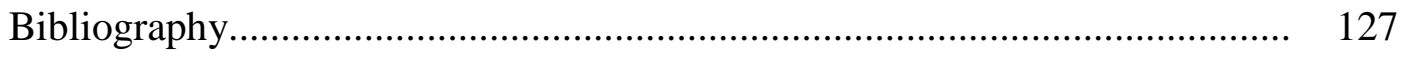




\section{Chapter 1: Introduction}

The United Nations' treaty, titled Convention on the Rights of the Child, brought international attention and commitment to the right of each child to be heard in general and specifically in the healthcare arena. Approximately 27 years ago, representatives from 190 nations made a promise that they would do everything in their power to protect and promote the rights of children to survive and thrive, to learn and grow, to make their voices heard and to reach their full potential (UNICEF, n.d.a,). Strides have been made to keep this promise, yet much work still needs to be done. UNICEF (United Nations International Children's Emergency Fund, now called the United Nations Children's Fund), has provided major support for the treaty by funding research on the rights and well-being of children in a wide range of contexts, including for example, adoption, education, terrorism and sexual exploitation (UNICEF, n.d.b). More recently, in 2002, the United Nations held a Special Session of the UN General Assembly on Children, at which many nations of the world committed themselves to a series of goals to improve the situation of children and young people (UN General Assembly on Children, 2002). It is the intent of the United Nations Children's Fund to support the belief that children need to be encouraged and enabled to make their views known on issues that affect them, knowing that the premise of 'A World Fit for Children' will only be accomplished with the full participation of children and young people (UNICEF, 2003). "The provision of quality care in health services tailored to children's preferences means that health professionals have a responsibility to ensure children's rights, and that a child is encouraged and enabled to make his or her view known on issues that affect them" 
(Soderback, Coyne, \& Harder, 2011, p.100). To date, none of this research has included the voice of the hospitalized child.

In a separate body of literature, a number of researchers, however, have begun to capture the voice of the child in studies related to the communication between nurses and children and its impact on the emotional and physical well-being of children in a hospital setting. In terms of negative impact, researchers have found that hospitalized children up to the age of 17 , when left out of discussions and decisionmaking, felt ignored, suppressed and powerless because they were not acknowledged as important (Coyne \& Gallagher, 2011; Livesley \& Long, 2013). The marginalization of hospitalized children was seen as their voices were not heard in efforts and calls for help and requests for preferences (Lambert, Glacken, \& McCarron, 2010). The nurses in these studies appeared to lack characteristics that are connected with what one might call an approachable nurse.

In terms of positive impact, researchers found that some instances of communication between nurses and children have been linked with establishing trust, creating a sense of value, worth and self-respect, lessening fear, alleviating anxiety and relieving stress (Coyne, 2006a; Lambert, Glacken, \& McCarron, 2008; Pelander, Leino-Kilpi, \& Katajisto, 2007). A variety of terms have been used to describe the characteristics and behaviors of the nurses involved in these interactions. For example, kind and cheerful nurses were found to relieve the stress of children (Pelander et al., 2007) and, when children were allowed to be autonomous in the hospital, positive outcomes ensued (Coyne, 2006b). The language of the healthcare provider along with the ability to make time to listen to the child were found to be 
essential in alleviating anxiety and creating a safe environment for the pediatric patient. Other researchers found that allowing children to participate in healthcare decision-making created a sense of value, worth and self-respect (Lambert et al., 2008). In a study by Spanish researchers, (Pena \& Juan, 2011), hospitalized children described nurses who communicated well as those who showed empathy with laughter and humor, used child friendly language and told personal stories. The nurses served as distractors in stressful and anxious situations. They showed interest in the needs and well-being of the child. Coyne (2006a) identified pediatric nurses who demonstrated therapeutic communication as those who were supportive, patient, gentle, cheerful, communicated openly and provided privacy. Finally, Coyne and Kirwan (2012) identified the characteristics of supportive nurses from children as those who are nice, kind, gentle, caring, funny, strict and always good listeners. Such descriptions would seem to reflect nurses who were highly approachable, although the concept of approachability was not mentioned and there is, to date, no explicit definition of the concept that can be used in relation to pediatric nurses. The aim of this study was to explore the perceptions of hospitalized children regarding the concept of an approachable nurse in relation to characteristics and behaviors along with potential impact.

This study used an exploratory, qualitative research design, including semistructured interviews with school age children who are or have been on an oncology unit to address the following research questions.

1. What are children's general perceptions of nurses who they think and feel are approachable? 
2. How do children describe the characteristics and behaviors of these nurses?

3. What do children think is the impact of having nurses who are approachable during their hospitalization?

\section{Significance of Study for the Discipline of Nursing}

The research completed contributes to nursing knowledge and provides insight from the perspective of the hospitalized pediatric patient. The author wished to hear the voice of the child and was able to elicit characteristics and behaviors from the perspective of the pediatric patient in relation to both verbal and nonverbal communication with the nurse during encounters on an oncology unit. The findings can contribute to the further development of a nursing typology described by Kim (2015). Kim (2015) described a nursing typology which includes four domains: client, client-nurse, practice and environment.

The practice domain refers to the intellectual/cognitive, social, behavioral, and ethical aspects of care performed by nurses (Kim 2015). How nurses use knowledge to transfer knowing into doing correlates with cognition to action, and undergirds the practice domain. In this domain, nursing knowledge is discovered through our understanding of how nursing actions affect the lives of clients by influencing outcomes, both positively and negatively. To improve nursing knowledge at the practice level, the purpose of this study was to gain a deeper understanding of effects of the approachable nurse on the pediatric patient.

The practice domain offered the author an opportunity to focus solely on the perceptions of the hospitalized child in relation to the presentation and behavior of the 
nurse regarding approachability. The presentation and behavior of an approachable nurse from the perspective of a child was described. What makes a nurse approachable and easy to talk to was elicited in this study. Themes emerged in relation to feelings of connectedness, comfort, trust and control in contrast to those of fear, anxiety and dependency. The practice focus enabled the researcher to identify the behaviors and characteristics of an approachable nurse in the context of the hospital setting.

Kim (2015) emphasized the aesthetic dimension of nursing practice which infers the importance of the self-presentation of the nurse. "Self-presentations in practice are expressions made by nurses through physical, behavioral, and discursive actions in their relationships with clients and in specific clinical situations" (Kim, 2015, p. 95). The art of this expression is perceived individually by the client and therefore important to gain the impressions and perceptions of the patients to attain best practice. Kim (2015) identified three principles of aesthetic rationality known as unity, harmony and finesse. Unity emphasizes the need for the multiple expressions of the nurse to reflect his/her underlying attitudes toward specific clients in specific situations (Kim, 2015). Harmony requires that the nurse align his/her behaviors with the individual needs of the client and in relation to the specific context of the situation (Kim, 2015). Finally, finesse is essential to assure authenticity of nursing actions. Improved and conscious nursing impressions as stated by Kim (2015) will "elevate the quality of nursing to a higher level” (p. 99). The findings of this study provide knowledge focused on the art of pediatric nursing care and provide insights into the kinds of self-presentation that the hospitalized school age child perceives as 
approachable.

The existential dimension of nursing practice identifies the importance of nursing presence in the clinical setting (Kim, 2015). This dimension of the practice domain is particularly relevant to this study as it "refers to how nurses engage with the world and comport themselves in clinical situations projecting their identities and meanings of selves, and revealing habits of their beings" (Kim, 2015, p.100). The presence of the nurse is individually related to the context of the situation.

In order for nurses to be present in a clinical situation, Kim (2015) identifies three principles of existential rationality as authenticity, particularism and understanding. Authenticity requires that the nurse be true to oneself creating actions that are genuine and specific to the individual patient (Kim, 2015). This nursing action is based on the caring aspect of the profession as opposed to acting simply to fulfill and complete a task. Within this study, the children report the need for an approachable nurse to exhibit behaviors and expressions that show the true self. Particularism refers to "the position that takes every situation as a particular instance with unique characteristics and presenting conditions" (Kim, 2015, p. 101). This principle requires that nurses don't standardize the role but individualize to the specific needs of every patient under each circumstance. Specifically identified in this study, the children describe characteristics of the approachable nurse as one who meets needs in a creative and distinctive manner. Understanding as the third principle of existentialism implies that the nurses grasp the true meanings of their actions, the patient and the situation. The approachable nurses in this study were described as listening, understanding and then finding ways to help in a caring way. Kim (2015) 
reflects that nurses must have comportment which requires the principles above to guide the existential dimension of nursing practice.

The practice domain allows the researcher to grasp the understanding required to know what the perceptions of hospitalized children truly are in relation to the concept of approachability to improve nursing practice. Findings created knowledge surrounding the impact of the approachable nurse along with his/her characteristics and behaviors based on the perceptions of school age children age 6-12 years, in the context of the hospital setting. Nursing practice, according to Kim (2015), "is a form of human service, which is specifically anchored on the benefits of others, requiring the practice to be intentional, thought-out, and goal-directed" (p. 4). From the angle of the practice domain, the researcher was able to utilize symbolic terms as well as physical ones in hospitalization and illness experiences to discern the concept of approachability and identify the characteristics and behaviors brought forth from the perceptions of the pediatric oncology school age patient as currently, there is a paucity of information on this topic. The findings created an awareness of the perceptions of the inpatient child to possibly enhance nursing practice.

Within the context of this dissertation, a clear progression of information will be provided. Chapter 2 will include a literature review and previously completed scholarly work related to this topic. In Chapter 3, the methodology of the study will be discussed with specific modes of data collection and analysis along with sample selection and trustworthiness. The findings and discussion will be shared in Chapter 4. In Chapter 5, a summary, conclusions and implications will be presented. All material used and obtained to achieve institutional review board approval will be listed 
in the appendices at the end of the document. A full list of references will support the foundation of this study. 


\section{Chapter 2: Literature Review}

\section{Rights of the Child}

In November of 1989, the Convention on the Rights of the Child was held in New York and noted for having established the world's most ratified human rights treaty. During this convention, 190 countries agreed that children have the right to be able to express views freely in all matters that affect them and should be treated with dignity and respect in all situations, including participation in informed decision making. In an attempt to curtail the abuse and neglect of children, government officials came together to create an agreement to secure the safety and dignity of all children. This treaty was an extraordinary attempt to affect all aspects of the lives of children addressing issues related to many aspects of the life of a child from parental guidance to adoption, education and issues related to health care.

This treaty contains 3 parts and 54 articles. Part I included articles 1-41 which in general delineated the specific rights of all children. This included definitions of terms used along with the issues related to discrimination. Statements were made in this section regarding the need for all parties to assure the best interest of all children along with the right to life and individual identity. The right of each child to remain with their parent unless there are situations of abuse is stated in addition to the necessity of all children to be protected from all forms of abuse. Children are required to have the ability to express views freely and be provided with privacy, dignity and respect particularly in relation to mass media. Statements within this section of the treaty are directly related to the right of the child to be heard. In Article 12, it is stated that "Parties shall assure to the child who is capable of forming his or her own views 
the right to express those views freely in all matters affecting the child, the views of the child being given due weight in accordance with the age and maturity of the child" (UNCRC, 1989b). In addition to the right to be heard, the child's right to freedom of expression is included in Article 13; "this right shall include freedom to seek, receive and impart information and ideas of all kinds, regardless of frontiers, either orally, in writing or in print, in the form of art, or through any other media of the child's choice" (UNCRC, 1989b). In relation to the hospitalized child, the treaty states in Article 24 that the child has the right "to the enjoyment of the highest attainable standard of health and to facilities for the treatment of illness and rehabilitation of health" (UNCRC, 1989b). Health care providers, must "ensure that all segments of society, in particular parents and children, are informed, have access to education and are supported in the use of basic knowledge of child health" (UNCRC, 1989b) whereby affirming the right to information. Finally, according to Article 24, appropriate measures must be taken to "abolish traditional practices prejudicial to the health of children" (UNCRC, 1989b). This statement confirms the idea that children should not be viewed as people with no voice, but provided with the dignity and respect that every human being deserves.

The first part of this treaty also includes the rights of all disabled and refugee children along with assurance of the highest attainable medical care to all young people. Education that is free and within reach along with freedom of minorities to expression is specified. Play is cited as a necessary right of children in addition to their protection from economic exploitation related to work safety, conditions, age and hours of employment. Finally, drug trafficking, imprisonment and sexual exploitation 
are identified as areas in need of vigilant protection for all children.

Part 2 of this treaty encompasses articles $42-45$ to establish a committee on the rights of the child within each state to realize the obligations of the convention. The process of election and term limits along with accountability reports are identified. The final section of this treaty, Part 3, articles 46-54, reports the regulations surrounding the convention itself and opens the treaty, in many languages, to all countries for ratification.

Significant research is continually taking place to support and enhance the Convention on the Rights of the Child. This research is under the umbrella of UNICEF (United Nations Children's Fund, formerly United Nations International Children's Emergency Fund) and is published by Innocenti Publications. Researchers have focused on a wide range of topics, including for example adolescent wellbeing, child's rights governance, and child's rights in the digital age, children in high income countries, education of children, parenting, violence affecting children. To date however, none of this research has involved the voice of the hospitalized child.

In order to comply with the rights of the child in health care settings, communication becomes a central point of focus for hearing and understanding the voice of the hospitalized child. The standards of practice for the pediatric nurse thus, need to highlight the nurse's role as an approachable health care provider and a facilitator of communication. Researchers, primarily in Europe have begun examining existing patterns of communication between nurses and hospitalized children and have found some positive effects of good communication between pediatric patients and what appear to be approachable nurses and some negative consequences that ensue 
when nurses create an environment wherein comfort and therapeutic communication does not exist.

\section{Negative Effects of Poor Communication}

There is evidence in the literature of the negative consequences of poor communication and what appears to be a lack of approachability between nurses and hospitalized children. In 2013, Livesley and Long completed an ethnographic study and within the voices of the hospitalized children found that if nurses are not in tune to the needs of the children, the staff and the children work towards different goals and experience different realities. The children in the study encountered nurses who created a negative experience by having requests for help ignored and turned to shouting and calling out for help. Poor communication in this study led some of the children to resist dehumanization with the stronger more resilient children persisting while the other more shy and quiet ones often had needs unmet. In a study by Lambert et al., in 2008, the researchers found that often when poor communication persisted, children were overshadowed and placed in the background by parents and health professionals. The children in this study reported that they were often left out of all discussions and nurses and doctors were too busy to talk to them. Another piece of exploratory work was completed by Brady (2009) who investigated the perception of hospitalized children regarding the "good" versus the "bad" nurse and found that the 'bad nurse was 'bad tempered', 'bossy', 'angry', 'grumpy', 'moaning', 'shouted', and did not listen to them.” (p. 548)

The negative consequences of poor communication between nurses and hospitalized children were more directly addressed in the following studies. Coyne 
and Gallagher (2011) found that children often spoke of providing preferences to nurses and health professionals but were frustrated because these preferences were often ignored and not acknowledged, creating a feeling of suppression. These children reported negative feelings of being "sad, disappointed, confused, angry, worried, shocked, betrayed, lonely, ignored and rejected" because of the lack of involvement in the communication and decision-making process (p. 2337). Coyne (2006a) found that poor communication led hospitalized children to feel a lack of control and powerlessness in the hospital setting. Bricher (1999) discussed the "silence of children's voices" in a hospital setting. In another study completed by Coyne (2006b), the researcher found that health care providers used language to exert power by talking over children. These children felt upset, angry and depressed when health professionals ignored them.

\section{Positive Effects of Therapeutic Communication}

Researchers have begun to show that the "promotion of children's autonomy leads to enhanced wellness and improved health outcomes" (Pelander et al., 2007, p. 185). Pelander et al. (2007) also noted that nurses who were supportive, patient, gentle and cheerful; communicate openly and provide privacy help to ease the stressors of children during hospitalization. Lambert et al. (2010) reinforced the need for the voice of the child to be at the forefront. These authors found that child participation in decision making and in all matters that affect them was a key factor in preventing the isolation and marginalization of hospitalized children.

In another study Coyne (2006a) found that the promotion of children's autonomy led to the enhancement of wellness and resilience in children and positively 
influenced health outcomes. The way in which a nurse self-presented to a hospitalized child was directly related to therapeutic communication. Coyne (2006b) reported that communication has a substantial role to play in giving children a voice within the healthcare setting and that the lack of information exchanged between children and healthcare professionals can only lead to confusion and fear.

Bricher (1999) reported that the behaviors of the nurse were critical in establishing trust and enhance cooperation. Coyne, Amory, Kiernan, and Gibson (2014) reported additional positive outcomes with good communication and welcoming behaviors of nurses in a hospital setting with children. The researchers found that nurses who encouraged the autonomy of a hospitalized child helped prevent feelings of loss of control and that helping children to express their fears and concerns and responding to those concerns is essential for successful outcomes. Coyne and Kirwan (2012) found that when nurses used child-friendly language, listened and responded to the questions of the hospitalized child and provided information to children before procedures, the fear of the unknown was reduced. Specific characteristics were identified by Brady (2009) when children described the "good" nurse. These children reported sensitivity to the nurse's tone of voice and body language. Many stated that "good nurses did not shout and used a 'nice', 'calm', 'relaxed', 'cheerful', 'kind' tone of voice to speak to them.' (p. 538). From the perspective of these children, the behaviors and language of the nurse provided a safer environment and significantly reduced their anxiety. Interviewing a 7 year old child, Coyne and Kirwan (2012) reported the child's response "My wish is that doctors and nurses talk to me" (p. 298). 
Additionally, researchers have found support for the positive impact of what they call therapeutic communication with children in a hospital setting. Coyne and Gallagher (2011) reported that valued and happy children were less anxious in the hospital. The researchers also found children reporting that they appreciated nurses who were friendly, attentive and willing to talk to them. The children found these nurses created an environment wherein they felt comfortable enough to ask questions freely and be involved in decision making. These authors determined that the key factors in therapeutic communication were the style and behaviors of the nurses.

\section{Concept Analysis of the Approachability of the Pediatric Nurse}

A modification of the Hybrid Model of Concept Development was used to conduct a concept analysis of the term approachability. Within the Hybrid Model, there are 3 phases: the initial Theoretical Phase, followed by the Fieldwork Phase and the Final Analytical Phase (Schwartz-Barcott \& Kim, 2000). The Theoretical Phase includes the selection of a concept to create a loose definition along with a literature review to map out the essential elements. During the Fieldwork Phase, empirical data is collected, through participant observation to describe and define the selected concept. In the third Final Analytical Phase, the researcher steps back, re-examines the definition of the concept in light of the literature reviewed in phase 1 and the empirical data gathered in phase 2 , and writes up the analysis.

The need for an analysis of the concept of approachability arose when the author recognized that the definition of "approachability" was unclear and that there was a need to describe the characteristics and behaviors of an approachable nurse from the perspective of the hospitalized child. This analysis would be used create a greater 
understanding among health care practitioners. Another need for analysis revolved around the necessity within research to develop a tool for measurement. The emphasis in the model is on eliciting elements indicative of approachability to glean an ability to measure the concept.

To initiate Phase I of this concept development, the concept of approachability was searched to ascertain data available related to hospitalized children and pediatric nurses. Initially, the Web of Science data base and then The CINAHL (Cumulative Index of Nursing and Allied Health Literature) were searched from 1995 through 2013 to identify any literature on the concept of approachability. Search terms utilized were "approachable", "children", "hospital” and "nurses" with "approachable” as the primary search term, then "nurses", "children" and "hospital" to refine search with multiple variations. This was augmented by hand searches of the references cited in each article.

A small body of literature was found in the social psychology domain related to adult to adult interactions and within the nursing disciplines related to nurse-adult interactions and nurse-child interactions in a hospital setting. Within the realm of the social psychology literature, researchers focused on adult participants to define the concept of approachability. These researchers used college students to judge the approachability of young adults in a laboratory and experimentally designed studies. Within these studies, adults were placed in a room and given standard pictures depicting people with happy, neutral and angry faces along with differences in body language and gender. They were asked to identify the photo of the facial expression, body stance and gender they would be most likely to approach. The researchers 
focused mainly on facial expressions including faces with happy, angry or neutral expressions (Campbell, Neuert, Friesen, \& McKeen, 2010; Miles, 2009; Willis, Palermo, \& Burke, 2011; Willis, Dodd, \& Palermo, 2013). They primarily found that happy faces were consistently associated and identified with those faces that were seen as approachable. One researcher focused on the difference between facial and body movement (Willis et al., 2011) noting that facial expressions were identified by subjects as more significant when judging approachability. In another study, a smiling female was found to be more approachable than a smiling male (Miles, 2009). These studies present the impression that the smile is most noteworthy when adults judge the approachability of another adult. Within this literature, there was no explicit definition of the concept of approachability but the above facial and body movements were identified as major characteristics of a person who was seen as approachable

In terms of the nursing literature, approachability has neither been identified nor defined as a scientific concept. At the same time, some characteristics of approachable nurses such as those who are easy to talk to, interact well and create a positive experience for children in the hospital were implied in the literature.

In research studies, children were engaged in interviews that were informal and often included game playing and drawing to further gain knowledge and insight from the perspective of the child. The majority of this research was conducted outside the United States in Ireland with additional contributions from Spain, Finland, England and Australia.

\section{Potential Characteristics of an Approachable Nurse}

Within the nursing literature, significant data have emerged that describe ways 
in which pediatric nurses have enhanced communication in a hospital setting.

Researchers have found that a nurse who presents in an appealing way, uses language that is child-friendly and clearly understood at an age-appropriate level (Coyne, 2006a; Coyne \& Kirwan, 2012; Lambert et al., 2008). Children have also identified nurses who were easy to relate to as those who allowed them to participate in some way in decision-making and encourage autonomy (Coyne, 2006a; Coyne, 2006b; Coyne et al., 2014; Coyne \& Gallagher, 2011; Coyne \& Kirwan, 2012; Lambert et al., 2008; Lambert et al., 2010). Many of these researchers have also heard from the voice of hospitalized children that nurses, who took the time to listen to them, heard their preferences and talked to them in ways that were not rushed but showed empathy and concern were kind, friendly and easy to talk to (Coyne, 2006a; Coyne \& Gallagher, 2011; Livesley \& Long, 2013; Pelander et al., 2007). The smile along with being playful and humorous were expressed by pediatric patients as traits amenable to a nurse who is warm and easy to communicate with (Coyne, 2006a; Pelander et al., 2007; Pena \& Juan, 2011).

Nurses easiest to talk to were described by hospitalized children as those who took the view of the child seriously, encouraged participation of the child in care and provided information pre-procedure to help the child to understand what would be happening (Coyne \& Kirwan, 2012; Pelander et al., 2007). Hospitalized children saw nurses who were easy to relate to as kind, warm, affectionate, respectful, educated and likeable, friendly and attentive (Coyne, 2006a; Coyne \& Gallagher, 2011; Pena \& Juan, 2011). Many of these children expressed the importance of the nonverbal characteristics of the nurse as being integral in self-presentation. Such attitudes and 
behaviors as protecting privacy, staying with the child, hugging or giving the child a kiss were mannerisms that expressed to the child a sense of care and true concern (Bricher, 1999; Coyne \& Gallagher, 2011; Livesley \& Long, 2013; Pelander et al., 2007; Pena \& Juan, 2011). Hospitalized adolescents have expressed a need for the nurse to allow them to have more autonomy in all aspects of care (Coyne et al., 2014). Other children have expressed the need for nurses to allow them to express their concerns and fears (Coyne, 2006b) and many children conveyed that they created a bond with the nurses who share personal stories (Pena \& Juan, 2011).

In the above literature, researchers discussed the phenomenon of communication between hospitalized children and nurses looking at the many ways in which the voices of the hospitalized children, when heard, can enhance the humanization of care. The concept of "approachability" begins to emerge from this literature as a person who is non-threatening, takes the time to listen, is not rushed, is flexible, smiles, takes interest in the ideas of the child, has a positive relationship with the parent/s of the child, allows the child to partake in decision-making when appropriate and utilizes language that is age and developmentally appropriate. It appears in the studies reviewed that there still is a need to gain more knowledge on the perceptions of the child in the hospital and within the context of communication between nurses and patients.

Researchers in the above studies generally used interviews with open-ended questions to capture the voice of the child. Drawings were sometimes implemented with the child as an aid in obtaining information that was developmentally appropriate and non-threatening. Characteristics and behaviors emerged by listening to children 
recount hospital experiences. Words and on occasion drawings illuminated the impact of the characteristics and behavior of hospital nurses on the experience of the child.

There are both similarities and differences in what constitutes approachability within the psychosocial literature. The findings from psychosocial researchers dealt specifically with adult subjects in a controlled laboratory setting with standardized pictures and presentations of prepared circumstances. These results were based on responses derived from an unnatural setting. Within the nursing literature, researchers have conducted informal interviews with children who were either hospitalized or had experienced hospitalization. These children were able to share their perceptions in relation to the hospital experience and describe the nurses and health care providers that cared for them. Results from both psychosocial and nurse researchers identified the smile as a primary characteristic of an approachable person. Nurse researchers were able to bring forth information that was much broader and detailed regarding behaviors and additional characteristics that described a nurse who presented in a welcoming manner. These findings from nursing include the impact these behaviors, characteristics and mannerisms had on the hospitalized child both during and after hospitalization.

\section{Phase II: Fieldwork}

As noted earlier, the intent of this phase is to collect empirical data related to the concept in this study. This phase was modified by using examples from practice to gain a beginning definition of approachability before collecting empirical data, in part due to the prolonged, in depth and highly specified requirements for gaining IRB approval for any empirical work with hospitalized children. 
Wilson (1963) provided a convincing technique for developing a definition from a concept. He borrowed from real-world examples, drawing from situations which clearly reflected, contrasted with or closely aligned with the concept to develop the definition (Cotton \& Schwartz-Barcott, 2016). The situations extracted were identified as model, contrary, borderline, and related cases. This researcher chose to use only model and contrary cases. Descriptive examples were used in the Fieldwork Phase from this researcher's clinical experiences as an advanced practice nurse and were used to develop a working definition of approachability. The two model cases presented contained all of the essential components. The contrary or contrasting case clarified the model case as it did not illustrate any of the essential components of the concept. By describing both contrary and model cases, the essential components of the model case were clarified and integrated into a theoretical definition.

Within Wilson's method, the author was able to describe model cases wherein essential characteristics and behaviors were reflected to bring forth an understanding of the concept. The model cases used were a female nurse from a university medical center in northern New England and a male nurse from a children's hospital in Southern New England. The nurse in contrast was a female nurse selected from a children's hospital in Southern New England.

The initial model case presented below, Sophia, was a nurse the researcher worked closely with both as a student nurse and licensed registered nurse while in nursing school and then at the start of her nursing career.

"Sophia Princess of Power." A Pediatric Nurse Practitioner in hematology/oncology at a university medical center in northern New England, Sophia 
could walk into a room and all were at ease. She was soft spoken and kind in her actions and words. At times I saw her walk into a room with a tiara and a "magical" wand in her hand. The children named her "Princess of Power" because she "always seemed to make things right." Her facial expressions were those that welcomed every child into her space. In the most intense situations, Sophia remained calm and knew exactly what to say and do. In the procedure room, I saw Sophia calmly talk to a child regarding the imminent procedure of a lumbar puncture to test cerebral spinal fluid for cancer and administer intrathecal chemotherapy. A sense of calm in a stressful situation soon occurred because of the way in which Sophia communicated and handled the situation. The child clearly understood within the realm of cognitive development what was to occur and developed ways in which to cope. Sophia was both knowledgeable and competent. She demonstrated her competence in knowledge and skills with information shared and skills efficiently and effectively completed. Her smile was soft and her hair neatly combed but soft around her face. It was not unusual to find Sophia sitting on a hospital bed with a child, talking about what was going on with a treatment or listening to the fears or concerns of a pediatric oncology patient. Sophia told me she was an atheist until she met and was affected by an adolescent male with a terminal form of cancer. He was very strong in his faith as a catholic and Sophia spent many hours talking to him. She told me he put all of his trust and faith in God and Sophia could not understand how an adolescent boy undergoing such an awful experience could have faith. Sophia was so struck by this young man that she had to go and find out what he called "God." This boy passed away at 17 and Sophia became a very strong practicing Catholic. This was an 
example of the quality time she spent with children of all ages in interactive engagement. Sophia was also the founder of a camp for children with cancer in Northern New England. At this camp, kids with cancer could be themselves, get the medical care they needed and most importantly, have fun. Sophia was a role-model who displayed approachability with exceptional therapeutic verbal and nonverbal communication.

The second model case was a male nurse who worked closely with the researcher in a children's hospital in Southern New England as she cared for hospitalized children as a pediatric nursing professor with her students.

“Crazy Ken.” The kids loved him. He was a playful nurse on a pediatric hematology/oncology/medical unit at a children's hospital and could put a smile on the face of any child. At one time, there was a 7 year old boy with kidney disease undergoing dialysis while awaiting a kidney transplant.

This child was in and out of the hospital frequently for urinary infections and many other urological procedures. A very sick little boy, he loved Ken. Ken would jump in bed with him and play hide and seek. After a serious team of medical doctors and residents would leave his room, Ken would look at this child and say "Do you smell that? That resident farted in your room!" The boy would start roaring with laughter. Nothing could be better than to see this very sick child smile! Another child, 6 year old little girl, with cancer being treated with chemotherapy started to walk down the hallway with her mom. Ken caught a glimpse of her and jumped down with the microphone and paged her to the nurses' station asking the "princess to report to the desk." The little girl began to smile and runs to Ken anxious to show him the 
IPAD she got from Make-A- Wish. Later, Ken was walking into a patient room with a black wig and bandana and the teenager, another oncology patient, was laughing, feeling at ease while also going through a very difficult time. Ken was playful, yet knowledgeable. His bedside manner was one in which both parents and children felt comfortable and at ease, knowing he cared and at the same time demonstrated quality care for the child. Ken showed his support externally also by participating in fundraising for the hospital, cancer walks and other supportive events for seriously ill children.

There were essential components that existed within both of these model cases. Behaviors of the approachable nurses were both verbally and nonverbally engaging and age appropriate for the developmental needs of the child. These nurses were willing to receive the child in a nonjudgmental and accepting manner wherein one did not overpower the other. The behaviors of these approachable nurses were sincere and exhibited real concern in ways unique to the personality of the individual. The model cases described above illustrated approachable as a nurse who made other people feel that he/she was receptive to another without reservation with behaviors that were spontaneous yet purposeful.

The contrasting case involves a female nurse named Lydia. She worked in a children's hospital in Southern New England where the researcher cared for hospitalized children with nursing students under her direction and supervision.

"Lydia." As I approached the unit, I wondered which nurses would be on for this shift. I was aware that there was one nurse that was not at all compatible with students and had a very poor bedside manner with patients. In she walked and I 
cringed. Lydia was of medium height and frame and weight. She had light colored hair and wore simple scrubs, not "kid-friendly." She kept her head down or looked forward. This nurse hardly ever smiled. When I saw her, I always said hello but she mumbled a hello with much effort under her breadth. She always seemed to have a problem or was complaining about something. I am aware that she was not married nor had children of her own. She disliked student nurses as her expressions of disgust arose when she was assigned to one. I, along with my students, had heard her make loud comments in front of the nurses' station, such as, "these are the worst nursing students we have ever had" and "I hope the next group is better than these." I tried not to assign a student to her as she had at times brought some of my students to tears. I once called her by the wrong name accidentally when I first started working there and she clearly stated "My name is... NOT ..." I apologized and she just walked away with a look of disgust. She walked into every patient room as if she did not want to be there. This nurse did her job but with very little communication that was even remotely therapeutic. I saw her talk to patients, even young children, with very little expression of empathy or concern. I had not seen her communicate with parents much, but she gave off an air of, I am here to do my job/tasks and get done and out. That was the feeling she portrayed. Her entire facial expressions were flat and with little emotion other than negativity and condescension. I had reported her behavior to the assistant nurse manager and I heard in return that many have reported her but there was nothing they can do because "the union protected her." This nurse was obviously qualified with knowledge and technical skill but had little to no bedside manner with communication related to children, parents or other health care providers. She never 
seemed happy. She made obvious negative comments about the staff and most everyone. She gave off negative "vibes" and showed everyone that she had a sense of entitlement in her actions. When she walked across the unit, she rarely smiled or gave off any sense of warmth or comfort.

In an attempt to create a theoretical definition, according to Wilson (1963), essential components are those found to be in the model cases but not in the contrary case. It is clear within the contrary case that it does not reflect the essential components of the concept. This contrary case described what approachability is not and therefore clarifies elements essential to the definition. This nurse did not exhibit behaviors that were verbally or nonverbally engaging. She was not able to receive the child in a nonjudgmental or accepting manner. Lydia overpowered the children she cared for and her behaviors were neither sincere nor exhibited any real concern for the child. In the case of Lydia, behaviors and characteristics resembled a nurse who is self-focused, not outwardly appealing, and presented herself in manner that neither resembled real compassion for the patient nor any desire to complete any task other than to get the job done. Creating a feeling of warmth with the essential need to display acts of kindness was not illustrated in the contrary case but ever present in unique ways in the model cases.

When evaluating the model cases, the researcher found that behaviors of nurses who appeared to be approachable were both verbally and nonverbally engaging and age appropriate for the developmental needs of the child. These nurses were willing to receive the child in a dynamic relationship wherein one did not overpower the other. The behaviors of these nurses were unique to the personality of that 
particular individual and displayed real concern and desire to meet the needs of the child and create a feeling of comfort and happiness. The two nurses who seemed approachable appeared to be able to connect in their own way with children whether it was in a playful or in a quiet manner. The approachable nurses appeared to suggest a feeling of receptiveness to another without reservation. The essence or fundamental characteristics of an individual nurse enabled him or her to be approachable to a child in a manner that was unique to the nurse. Each of the nurses expressed approachability in a distinctive yet sincere way, displaying behaviors that seemed to be spontaneous yet purposeful and created an experience for the hospitalized child that was welcoming and comforting. For these children, the impact of the behaviors was to minimize fear and anxiety which made them feel at ease.

\section{Phase III: Final Analytical Phase}

As mentioned previously, the researcher in this phase of the Hybrid Model compares and contrasts the phase one findings with the earlier literature review and writes up the final analysis. The researchers in the studies reviewed in Phase I discussed the phenomenon of approachability between hospitalized children and nurses looking at the many ways in which the voices of hospitalized children could be heard in order to enhance the humanization of care. The psychological literature brought forth the importance of the smile, relaxed, welcoming body language and the

possibility that gender, particularly female, was preferred when adults judged approachability. In the nursing literature related to pediatrics the researchers explored the descriptions from hospitalized children in relation to the experience and factors surrounding the nurse and other health care providers that created an environment that 
was welcoming and understanding of the children's needs and wishes. The children in these studies reported the importance of the smile, the need to be included in decision making and discussions, the desire to have preferences addressed and a nurse who was friendly and kind. The model cases in the concept analysis brought forth the importance of a nurse who received a child openly, encouraged laughter and joy and yet had the competence to ensure the child felt safe and well taken care of.

In order to communicate effectively, the researchers revealed that, based on identified verbal and nonverbal behavior, a nurse who self-presented in a manner that was welcoming would establish a therapeutic nurse-patient relationship and effectively communicate. Soderback et al. (2011) suggested the necessity of conducting research with children if health care providers want to find out their perspectives and truly engage in child-centered care. Based on this literature and concept analysis, an initial definition of the concept was formed. The approachable pediatric nurse is one who is non-threatening, takes the time to listen, is not rushed, is flexible, smiles, takes sincere interest in the ideas of the child, has a positive relationship with the parent/s of the child, allows the child to partake in decision-making when appropriate and utilizes language that is age and developmentally appropriate. It was clear from the studies reviewed that there was a need to gain more knowledge on the perceptions of the child in the hospital and across varying contexts and situations in regard to the concept of approachability.

This researcher has identified the need to gain greater insight into the perceptions of hospitalized children regarding the approachability of nurses and the impact of these behaviors. The following chapter will discuss the methods used to 
collect and analyze data along with sample selection and setting. 


\section{Chapter 3: Methods}

The perception of school age children regarding the approachability of pediatric nurses in an inpatient setting was the focus of this study. The specific research questions were:

- What are children's perceptions of nurses who they see as approachable on an inpatient pediatric oncology unit?

- How do children describe nurses who they feel are approachable?

- What do children think is the impact of having a nurse who is approachable during their hospitalization?

\section{Research Design}

An exploratory, qualitative, descriptive research design, including interviews with 7 school age children (6-12 years old) on a pediatric oncology service was used to answer the research questions. A qualitative descriptive research design was selected since researchers using this design have produced findings that were close to the data and helped to understand the experiences of the individuals (Denzin \& Lincoln, 1994; Sandelowski, 2000; Sandelowski 2010). Within this study, the children were able to recount personal experiences of events, which were significant to the child in relation to the approachability of the nurse, allowing the researcher to build knowledge, which in turn created a voice for the child. As a nurse researcher, I was able to develop a greater understanding of the individual perceptions, understanding "what was going on" from the descriptions shared by these 7 children (Marecek, 2003; Marecek, Fine \& Kidder, 1997; Morse, 2011; Streubert \& Carpenter, 2007).

In order to hear the voice of the child in a hospital setting, effective 
communication that is therapeutic both verbally and nonverbally needs to take place in an environment that is open, welcoming and accepting. This researcher sought to understand the perspective of the hospitalized child in order to promote and enhance the hospital experience. Additionally, recollections and insights from the children created a better understanding of the impact of approachable nurses. Awareness was formed of the possible effects of the approachable nurse on hospitalized children, both short and long term, related to anxiety, fear and re-hospitalization. Although there are a variety of methods to elicit information, the qualitative descriptive design was an ideal way to support this inquiry.

Unstructured interviews were selected because this method of data collection was most indicative for the generation of knowledge desired. Additionally, the researcher had years of experience in talking with hospitalized children and knew how to take the necessary time to speak with parents and children informally to develop the needed trust to engage in this type of data collection. Lastly, the flexibility of an unstructured interview allowed for conversational freedom.

\section{Setting and Participants}

The setting of this study was in a hospital in Southern New England, referred to in this study as Mercy Children's Hospital. Children from the pediatric oncology service who were of school age on the fifth floor of this hospital along with those from the ambulatory clinic, referred to here as the Sunshine Clinic were selected. This hospital was a 118-bed pediatric teaching facility affiliated with an Ivy League medical school. Interviews were held in patient rooms at times that were not identified as highly busy and populated along with convenient to the needs of the 
child, the parent, the caregiver and medical care.

The fifth floor had a total of 30 inpatient general care rooms along with a number of offices. Upon walking off the elevator to this unit, one could see the beautifully decorated family room favoring the color purple. The floor breaks off into three different pods, the red pod to the left, with corresponding red floor tiles and red décor, the blue pod straight ahead and the green pod to the right also with corresponding floor tiles and decor. This unit houses the pediatric hematology/oncology inpatients along with other general care pediatric patients of all ages with medical/surgical issues. Included on this floor was a treatment room wherein potentially painful or difficult procedures took place so that the child's room remained a safe place. The playroom was a very large room on this unit filled with games and toys wherein children of all ages came to play and have fun with big open windows that overlooked the city. There was a large, newly renovated family room on this floor that was donated by the parents of an oncology patient so that hospitalized children and family members can meet and enjoy time together in a comfortable living room style area with a kitchen stocked with donated snacks and coffee.

There were eight patient rooms on each pod, some single and others double. Single rooms were reserved for children requiring isolation precautions. Each bed space contained the child's bed, monitoring devices, a television with a program called “The Children's Network" where the children could engage in both fun and educational programs along with the ability to watch television stations and select a daily menu. Beside every bed sat a large chair that opened up to a bed so that a parent could remain with the child 24 hours a day. A closet, desk space and full bathroom 
were also included within each room. On the wall next to each bed hung a wipe board so that with each shift, the nurse and care providers could write down their names so that the child and parent would know who would be caring for them at all times. Every child was given a remote device to regulate lights, television and call on the nurse when needed. Each pod was positioned in a half circle format so that the nursing station was central and the patient rooms were all around allowing the nurses and patients full view of each other when curtains were open in the patient rooms. Along the hallways, there were wagons and carts to transport children in manner that was entertaining to the patients.

The Sunshine Clinic was housed on the first floor of Mercy Children's Hospital wherein all outpatient therapy and treatments were provided to children with cancer. Within the Mercy Clinic, there were several private rooms along with other spaces to allow for evaluation, treatment and play. Walking into the clinic, a receptionist would greet the patient and family. The waiting room was immediately to the right filled with toys and activities to keep the children occupied while receiving treatment or waiting. A child life therapist was assigned specifically to meet the needs of these children. The clinic had private exam rooms and open spaces with curtains to allow the child and family to choose a space for treatment wherein they felt most comfortable. The offices of the nurse manager, supportive staff and physicians were also included in the clinic. Most of the children and families seemed to gather and remain in the waiting area for treatments following a private evaluation in an exam room. The children engaged in activities with each other while the parents seemed to converse and provide mutual support. 


\section{Gaining Entry}

Although full support was provided from the hospital staff, gaining entry to initiate data collection was a challenge from the institutional review board of this children's hospital. The paperwork and process began in August and because of multiple requests for revisions, approval was not received until the middle of December. The researcher worked with the IRB liaison, following all steps as necessary but there were certainly unexpected delays. An institutional joint agreement was required from the University of Rhode Island and the Hospital to allow the hospital approval and research study guidelines to dictate the research and secure subject safety. This agreement was in the final stages of approval and so delayed time needed for final approval of this study. Data collection began at the end of December. Additionally, due to insufficient recruitment, a request was made about half way through data collection to the IRB to expand recruitment to the Sunshine Clinic.

\section{Participants}

Following approval from the respective hospital and the university institutional review boards, a purposive convenience sample of school-age children (6-12 years) were recruited for this study. Participants were selected who had been diagnosed with a form of cancer, were proficient in English and without cognitive and/or developmental impairment, medically stable and had been hospitalized at least once previous to the interview. In order for the researcher to contact the parent for recruitment of the child, the charge nurse was required to obtain a Consent to Contact (Appendix D) from the parent to deter any sense of coercion to participate. Once consent to contact was received, the researcher contacted the parent and all parents 
and children signed IRB consent forms (Appendices E \& F).

School age group was chosen because they are often eager to please and willing to engage with others. Based on Erickson's psychosocial stages of normal development, children at this age are attempting to overcome the conflict of industry versus inferiority (Newman \& Newman, 2012). During this period, children are striving for the desire to be happy, establishing the ability to succeed in schoolwork, play and friendships (Newman \& Newman, 2012). In relation to this desire for happiness, these children were selected because open and free discussion would provide them with an opportunity to create a positive change in their hospital experience. As opposed to other age groups, it was anticipated that these children would be more willing and interested in cooperating and participating in the study. In addition to psychosocial development, children of this age group are undergoing cognitive development. According to the work of Piaget, during this period of formal operations, children are beginning to apply logical reasoning to all aspects of life (Newman \& Newman, 2012). They are beginning to understand the effects of social conditions and those behaviors that can change an outcome. It was anticipated that children of this age group would be able to share how they perceived an approachable nurse and how this directly affected their care. Because of their level of development, the researcher projected that these children would be able to clearly express themselves, through an understanding of language, perceptions, behaviors and characteristics. Children at this age often desire to please and are relatively uninhibited and blatantly truthful. Additionally, this age group was chosen because they would not yet be at the stage of adolescence wherein participation may not be 
desired but yet have sufficient cognitive ability to respond to interview questions.

Studies by other researchers included all age groups. In contrast, this researcher acknowledged the distinctive differences in cognition and behavior within the stages of growth and development and decided to focus solely on school age children to isolate findings towards their perceptions.

Different aspects of this proposal were directly affected by the age group selected. The formulation of interview questions was based on the cognitive development of a school age child. Language was taken into consideration to assure understanding and enhance the ability of the child to respond honestly and accurately based on their individual perceptions. Questions were prepared in a general manner with probes if needed to help each child to better understand. Flexibility in the interview allowed the school age child to proceed in the direction desired. The researcher was able to integrate drawing into the interview as this is an age appropriate measure to enhance the engagement of children age 6-12 years. Some parents/guardians were present and others were not during the interview based on the wishes of both parties which allowed the child to feel secure and safe during the meeting time. Additionally, assent was attained from the child giving the participant control over involvement. It was the hope of the researcher that these interventions would allow for a comfortable environment for participant involvement.

\section{Recruitment}

Following approval from the respective hospital and the university institutional review boards, recruitment flyers (Appendix C) were posted on all three pods of the fifth floor, the family room and the play room along with the waiting room in the 
Sunshine Clinic that briefly described the study and provided the researcher's contact information. This researcher obtained a floor census at least twice a week, reaching out to the assistant charge nurses to ascertain possible participants who fit the age group and required characteristics. The researcher met with the assistant charge nurses to assure their understanding along with the understanding of all staff nurses regarding the goals and aims of this study. Additionally, contact was maintained with the nurse manager of the Sunshine Clinic, in a similar manner to ascertain possible participants and assure comfort and understanding of the clinic nurses and the manager. All questions were answered to assure compliance and cooperation. Notes were kept regarding ages, conditions and related participant information in a journal.

The researcher met with potential participants and parents to discuss the aim of the study, inviting participation. There was no hesitancy on the part of any child or parent to participate. All who were approached by the charge nurses both inpatient and outpatient agreed. The parents were pleasant and amenable. All of the children were eager to talk but based on the personality of each child and their current state of health, enthusiasm during the interview differed. All information regarding involvement was provided to both the potential child participant and the parent in detail, answering any and all questions prior to signing consent and assent. No parent concerns were raised; therefore, assent (Appendix F) was obtained from the child and then consent (Appendix E) was obtained from the parent or legal guardian. All parents were invited to join the meeting, being present for observation but not participation. Three meetings were held in the patient's hospital room and four in exam rooms in the clinic within this urban children's healthcare facility. Nurses were 
consulted and appointments were scheduled with the researcher and the parent/child involved in this study at the time of meeting or on the phone when obtaining agreement to participate.

\section{Data Collection}

Information was gathered in this study by using semi-structured, open-ended interviews. All interviews were conducted by this researcher. An interview guide (Appendix G) was developed based on the research questions, literature review and this researcher's twenty eight years of experience communicating with children as a pediatric nurse and a pediatric clinical nurse specialist.

Unstructured interviews were chosen because of their flexibility, fluidity and the opportunity to obtain the information required yet at the same time, giving the participants the freedom to provide as many answers and explanations as they desire (Bernard \& Ryan, 2010). This form of interviewing provided a fitting medium to collect information regarding the topic of communication with hospitalized children in an acute pediatric setting. The interviews were conducted in an unstructured manner, intending to add depth and breadth to the information obtained. The aim was to foster a "human-to-human relation with the respondent and the desire was to understand rather than to explain" (Fontana \& Frey, 2000, p. 654). Unstructured interviews were selected in order to obtain a description and understanding of the behaviors of an approachable nurse through the child's perception of them without imposing structure or strict guidelines in collecting the data. The researcher intentionally kept questions open to allow the child to take the lead. The goal of this research was to identify the child's perspective of "approachability", without adherence to a strict format as one 
would see in a more formal interview process. In order to engage a child in conversation to casually elicit responses to developed questions, the researcher eliminated the formality and created a setting where the child felt comfortable and at ease.

This researcher chose unstructured interviews because this method of data collection appeared to be most indicative for the generation of knowledge desired. As mentioned by Fontana and Frey in 2000, there are several steps to achieve in order to effectively complete an unstructured interview. Accessing the setting was the first step. This author was able to access the pediatric oncology patients who were of school age on the fifth floor of this hospital initially and then in the Sunshine Clinic as soon as IRB approval was received. Preliminary discussions took place with staff and administration in both the Sunshine Clinic and on the inpatient unit and full support was offered.

Understanding the language of the children was essential to effectively engage with them in conversation. Within the format of these unstructured interviews, this researcher considered and implemented language that was cognitively and developmentally appropriate for school age children, rephrasing as needed based on the child's level of understanding. For example, the word approachable was exchanged with "easy to talk to," "made your stay easy," "the perfect nurse" and "your favorite nurse." Additionally, it was the responsibility of this researcher to decide how to present and introduce herself in attire, voice and behaviors that were not intimidating to the child. The researcher chose not to wear scrubs or any form of a hospital uniform but casual/professional dress that promoted a relaxed environment. Due to the fact that both the child and parent knew the researcher was coming, there 
was no surprise and introductions were completed by the nurse manager in the clinic or by the researcher herself on the inpatient unit. Introductions were always with a smile and brief conversation about how both parent and child were feeling.

Getting to know the parent and child initially was important to create an atmosphere of comfort. The researcher shared information about herself and the study to allow the child to feel relaxed and at ease. Gaining the trust of subjects may have been difficult as hospitalized children most often are guarded for fear of harm in an unfamiliar environment but this researcher was able to engage in dialogue with ease. Three interviews took place in the child's hospital room and four in a private space in the clinic; both locations being a safe and mutually agreed upon location for the child. The ability of this researcher to gain trust was essential to the success of the interviews and, once gained, trust needed to be maintained (Fontana \& Frey, 2000, p. 655). The researcher followed through with the plan to interview, draw and provide the child with a gift card in appreciation. A reason for selection of unstructured interviews revolved around the idea that the researcher has a good report with children and would take the necessary time to speak with parents and children informally prior to starting in order to develop the needed trust to engage in this data collection.

Developing rapport with hospitalized children was critical so that this researcher could fully understand the situation and viewpoint from the perspective of the child via the unstructured interviews. Rapport was gained with the relaxed demeanor of the researcher, the comfortable smile and unbiased acceptance of all subjects and parents. Genuine concern for the parent and child was also expressed by the researcher while attentively listening and responding with compassion and respect. 
I tried, as the researcher, to place myself in the role of the child who was hospitalized to gain a real sense of the meaning in order to obtain the child's perception of approachability. Conversations were taped in order to eliminate the need to write notes while the child was speaking. The flexibility of an unstructured interview allowed for conversational freedom for all but one child who even with continual reassurance appeared to feel insecure.

Drawing was selected as an appropriate mode to assist in data collection as it has often been referred to as the universal language for children and can serve as a valuable tool for children to express their experiences (Rubin, 1984). Children who are of school age, for the most part, will gladly engage in a drawing activity with someone who is willing to take the time to sit with them and talk and color. All of the children interviewed were both willing and interested in coloring. This activity was able to aid in the development of rapport as discussed previously and enabled trust. Drawing was mentioned initially as one of the activities included within the interview and seemed to reinforce rapport. It has been found to be one of the best ways for children to express themselves. The thoughts, beliefs, fears and inner world of children can be expressed through drawing. The critical piece of this drawing technique was the discussion that surrounded the drawing. The experiences of the hospitalized child and their perception of the approachable nurse were often derived through conversation and therapeutic listening to the voice of the child in their explanation of drawings. A child's drawing can be a window, not only to the child's feelings about his or her illness but also to cognitive and developmental maturity, coping styles, and personality (Rollins, 2005). This became a reality with all of these 
children in relation to their perceptions of the approachable nurse.

Drawing was used as a tool to allow for the expression of perceptions of the approachable nurse to the children interviewed. There has been a great deal of research related to the use of drawing in the mental health management of children. Many have "used drawing techniques with children that are not specifically designed to assess, diagnose, or evaluate the child but to provide a way for the child to communicate issues, feelings and other experiences and to explore, invent and problem solve through self-expression" (Rollins, 2005, p. 204). It this study, drawing created a time wherein the children and the investigator were able to bond and the perceptions of the child on approachability were shared in a very simple yet effective and playful manner. Coloring and drawing were activities that children were accustomed to so therefore, this experience was able to generate an environment of familiarity in which to talk, listen and enable rich data collection.

The interviews were conducted at a time that was mutually agreed upon by the participant, parent and the researcher. A one- time private interview was conducted that lasted anywhere from 30 minutes to an hour. The parent/s was given the option to stay or leave. The mother of all three hospitalized children remained in the room while only 2 of the 4 clinic parents remained in the room during the interview. The researcher was aware that time arranged to meet must be open to changes related to the medical conditions of the child along with all physical and mental side effects that may occur spontaneously resulting in delay and possible cancellation/postponement. With two of the inpatient participants, Hobbs and Santa Claus, the researcher had to pause the interview for consulting physician visits due to health related concerns. 
During all patient interviews, time was provided for care to take place if needed during the interview. Carley and Hobbs unexpectedly had a visitor on one attempt to interview and therefore the researcher rescheduled without hesitation to assure the child that their enjoyment was priority.

All interviews were audiotaped and assigned a code number to protect confidentiality. The children were allowed to choose a pseudonym at the onset of the interview to be used to protect confidentiality. The taped interviews were professionally transcribed. In an effort to express appreciation to these children, a twenty dollar gift card was given to each child participating in this interview process. Based on the precept that researchers are co-participants in the data collection process, journaling was completed by this researcher at the end of each interview to allow for personal impressions of and reflections on the interview and to document any concerns or issues that occurred during the interview process. Additionally, journaling was critical to document the nonverbal behaviors of the children as they discussed their perceptions on the judgement of approachability of pediatric nurses.

\section{Data Analysis}

Analysis of the data was completed by utilizing qualitative content analysis. In Schreier's 2012 historical overview of content analysis, the author identified three phases, one prior to the formalization of content analysis as a research method and lasting from the 1600 s to the early 1900s; a second when content analysis emerged as a quantitative research method in the social sciences, with this phase lasting until the late 1940s and, a third phase that began a period of interdisciplinary and methodological elaboration that continues into the present. It was during this last 
phase, around the early 1950s that qualitative content analysis emerged.

During the first phase and as early as the 1600 s, Church potentates were concerned that non-religious material was being printed in the name of the Church and commissioned the content analyses of religious texts. A little later, with an increase in the popularity of newspapers and the rise of journalism, content analysis was used to address issues that were being raised about the objective and ethical content of newspapers. The second phase of progression within this method of analysis occurred when communication surfaced as a topic of interest for social scientists. The first concise presentation of concepts such as stereotypes, styles, values and symbols using the methodology of "content analysis" appeared in 1948 by Berelson and was then published in 1952 as the first systematic presentation of content analysis as a quantitative research method (Krippendorff, 2013). Schreier (2012) also described the third phase of content analysis development as a time when disciplines outside of communication such as education and political science began to use the method. During this time, greater attention was paid to the context of the situation wherein the communication occurred and the focus shifted from the words within text to the interrelation of characteristics.

A shift occurred in the mid-1950s when researchers using qualitative content analysis switched from a primary focus on the analysis of manifest data to one that included both manifest and latent data. Kracauer argued in 1952 that meanings are often more complex than simply words read, text must be read in detail to determine a clear meaning and frequency does not directly imply importance (Schreier, 2012). Researchers throughout the world criticized qualitative application yet others, 
particularly in England and the United States embraced qualitative application of content analysis. With the acknowledgement of different views of application, content analysis is now seen as a way in which both manifest and latent data can be examined.

A major step in conducting qualitative content analysis research is to determine the importance of manifest and latent data. Manifest data is used to examine the actual text in regard to the visibility of the words whereas latent data, in contrast, is used to explore the text in regards to the interpretation of underlying meaning and the interrelationship of the words (Downe-Wamboldt, 1992; Graneheim \& Lundeman, 2004; Kondracki, 2002). In manifest data analysis, the focus is on the words and literal text whereas in latent data analysis the text is investigated in relation to the context of the situation along with nonverbal cues from the subject. In this qualitative study, both manifest and latent data were used to analyze the text from each child. Each text included the transcribed interview, the researcher's journal notes, and any artwork produced by the child during the interview.

Several steps were conducted by this researcher to ensure accuracy and comprehensiveness of the data analysis. The author listened to interview audiotapes before transcription to initiate the process of immersion and to obtain a sense of the whole situation while reviewing the journal for the corresponding child. The tapes were transcribed verbatim through a medical transcriptionist who specializes in all forms of transcription. The transcriber who handled the transcription was completely aware of the sensitivity and confidentiality of the materials.

The analytic process began as the researcher listened to the audiotapes while reading the transcript to check for accuracy of the transcription. Journal notes from 
each interview were attached to the transcript to provide the reader with nonverbal behaviors, including gestures, posturing, eye contact, pauses, and any and all emotional expressions. A drawing completed by each child interviewed and the artwork were attached to the transcription and journal text for comprehension. A first read was completed to gain familiarity and identify initial impressions. A second read was completed of all text in relation to the first research question. The researcher sought to gain insight into the child's perception of nurses who were felt to be approachable. The aim was to ascertain the qualities of approachable nurses along with verbatim comments related to each nurse individually. The researcher perused the data to ascertain commonalities and record descriptions directly from the voice of the child. The researcher also utilized the time frame immediately following the dialogue to journal and analyzed each interview to assure sharp recollection of all conversation and behaviors that transpired. With each interview, the researcher documented general initial impressions, impressions regarding approachability and addressed each research question following multiple reads of the transcript while listening to the taped recording to become completely immersed in the data. In relation to the second research question, the author again re-read the interview text in search of descriptive words to attain manifest content to gain a description of nurses who the child found to be approachable. The text was again reread to address the third research question related to the impact of an approachable pediatric nurse on the hospitalized child. Here, manifest and latent data were used to describe how the behaviors of the nurse affected the child both during and after the hospital stay. The researcher and the chair of her committee coded the transcripts 
separately in relation to emerging themes and then compared coding. Changes were made if differences were found until there was complete agreement. On occasion, for example, the researcher and the committee chair would discuss different impressions of approachability after reading transcription. Codes were sorted into categories based on relationships. Direct quotes were taken from the transcribed interview to support the categories and provided descriptions using the participants' own words. Corresponding latent data and drawings were also incorporated to support codes and categories that arose. Drawings were not analyzed but used to gain a greater understanding of interview responses.

The sequence of steps described above was repeated for each child interviewed. This was followed by a cross interviewee analysis in relation to each of the research questions.

\section{Ethical Considerations}

Children in general are a vulnerable population. Every attempt was made in this study to secure and protect all of the children participating in the study. In relation to the principle of beneficence, this researcher was able to minimize harm and maximize benefits while gaining valuable knowledge to improve the healthcare of these children and future hospitalized children. Conversations took place in a kind and casual manner allowing the child to speak freely and securely with parents present. Although not needed, if at any time, the child wished to terminate the interview, he or she was assured that this would be completely acceptable and without consequence. All of the children were engaged and some in fact, were in no rush to end the interview. Again not required but if the child who was being interviewed had 
become upset, the interview would have stopped, the nurse caring for the child along with the assistant nurse manager would have been contacted and necessary support would have been provided. Fortunately, all of the children interviewed were pleasant and content. Being a qualitative study, the researcher was particularly sensitive and vigilant to the potential negative effects that might occur with in depth exploration and probing that takes place in an interview (Polit \& Beck, 2008), although there was no indication that any negative impact occurred in this study. In fact, all conversations were positive and well tolerated.

In relation to the ethical principle of respect for human dignity including the right to self-determination and full disclosure, informed consent was received from parents and assent from the child. With this in mind, all participants freely volunteered to participate in this study. Potential participants and their parents were informed of the purpose and aims of the study along will the method of data collection to ensure that potential participants and their parents would know enough to make a decision as to proceed or not to proceed (Seidman, 2013). Information was provided to both parents and children at an age appropriate level that was conducive to comprehension to ensure information was understood.

Justice was assured to implement the intention of fair treatment and privacy to all participants. Fair treatment required that this researcher honor the agreement to allow participants to withdraw from the study at any time without consequence. No child expressed the desire to withdraw in any way. The author adhered to compensation of a $\$ 20$ gift card in appreciation for time and willingness to participate. The researcher remained nonjudgmental and was aware and sensitive to the diversity 
present within the public arena of participant recruitment and remained respectful and courteous at all times (Polit \& Beck, 2008). Efforts were made to protect the confidentiality of all participants in this study. The listing of names associated with assigned pseudonyms was recorded on another piece of paper and kept separate from the rest of the study data. A code number and pseudonym were identified and attached to each interview and the pseudonyms were self-selected by the participants. The study records and audiotapes were shared with only 2 additional researchers who are dissertation committee members.

Participants were informed of the limits of confidentiality. The researcher clearly explained the possibility of subpoena along with mandatory reportable requirements. If there were any incidences related to child abuse or neglect, they would have been reported during the interview. The researcher was mandated to report to the Department of Children Youth and Families along with law enforcement officials. All measures were taken to ensure the safety and confidentiality of all child participants according to the standard ethical principles of research.

\section{Trustworthiness}

Within this qualitative research study, Lincoln and Guba's (1985) criteria of credibility, transferability and confirmability were used to help assure the trustworthiness of this study.

Credibility refers to confidence in the internal validity of the findings and the interpretation of the data (Lincoln \& Guba, 1985). The findings were based on the actual experiences of these children and transcribed with close attention to accuracy. This researcher read all transcripts that were typed verbatim from audiotapes while 
listening to tapes to ensure accuracy and carefully documented nonverbal observations in a journal. These activities helped increase the credibility and accuracy of the data collected. Credibility was also enhanced by inviting pediatric oncology patients to participate in this study as they frequent the hospital often and have current and past experiences in communicating with nurses. The purpose of this study was to ascertain the perceptions of children in relation to the approachability of nurses and these participants would likely have the most experience with nurses in an inpatient setting. By selecting these participants, the first step toward credibility was achieved. The selection of semi-structured interviews for data collection was an appropriate method as it allowed the researcher an opportunity to provide the children with questions guiding the collection of data but remained open-ended and flexible allowing the participants to describe and explain in their own words the approachability of nurses. Drawings helped the children talk about their perceptions of approachable nurses in an age appropriate and non-threatening way. By selecting a mode of data collection that was appropriate, credibility was enhanced.

Prolonged engagement with the data was another way that credibility was enhanced (Lincoln \& Guba, 1985). This researcher listened to all interview tapes and read transcripts and journals multiple times while viewing the drawings of the children to obtain the children's fullest perception of approachable nurses. The researcher took direct quotes from participant interviews to include in the findings as recommended by Graneheim and Lundman (2004) to enhance the credibility of the findings.

Transferability as noted by Lincoln and Guba (1985) was seen as the probability that the findings of the study would have meaning in other situations that 
are similar. In this study, transferability was achieved by providing descriptions of the setting and participants that are similar to all hospitalized children along with those having a diagnosis of cancer. Detailed descriptions were provided by the participants of experiences and perceptions. Direct quotes were also provided to assure authenticity and clarity of this qualitative study. Transferability was enhanced with detailed information about the setting and participants.

Confirmability refers to the potential agreement between two or more independent people about the accuracy of the data, relevance and meaning which infers the neutrality of the findings based on the responses of the children interviewed and not the researcher (Lincoln \& Guba, 1985). This researcher, along with her major professor, read all transcripts and journals and viewed drawings separately and then together discussing their analyses and were able to reach agreement on the findings. Readings immersed both to achieve a sense of the whole. Additionally, an audit trail of all records was kept throughout the process and reviewed by the major professor. Accurate documentation was maintained throughout all steps of the study and was available for review by the dissertation team. 


\section{Chapter 4: Results}

The results of these interviews elicited insights from the children that were both sincere and genuine regarding their perceptions of the approachable nurse. All of the children interviewed were able to express clearly and in their own powerful words, the impact of nurses' presence and style of communication and behaviors. All measures were taken to create an environment of comfort and safety during the interviews. The drawings were particularly effective as an age appropriate activity to engage the children and supplement the conversation. The study design and methodology were suitable and effective in gleaning the desired information.

There were seven school age children interviewed in this study. The children were between the ages of 6-12 years old including an 8, 9, 10 and 11 year old and 3 children who were 12 years old and included 4 girls and 3 boys. For all but one, English was their native language. For the one boy for whom English was a second language, one could not detect any form of accent or deficiency. In fact, this boy was more articulate and able to verbalize greater knowledge about the meaning of individual words than any of the other children. All of the children had been hospitalized at least once previous to the interview but 6 of the 7 had endured multiple hospitalizations related to their diagnosis of cancer. Even though the children were all in the same age group developmentally, the differences in personalities were striking and are elucidated in the following profiles.

\section{Individual Portraits}

"Santa Claus." I was entering the room of an 8 year old little girl with osteogenic sarcoma who had undergone excision of the tumor and chemotherapy. It 
was December 22, 2016. As I walked in, I saw a frail little girl curled up with blankets in her hospital bed with stuffed animals near her. Her mother and father were "switching off" as mom stayed the night and dad had brought her clothes. This child had a visible port-a-cath central line with many bags of IV fluid running. All children with cancer have a central line for the safe infusion of chemotherapy, blood products, and other required intravenous medications for treatment. Santa Claus had a nasogastric feeding tube in place, taped to her left cheek to supplement nutrition and administer necessary oral medications. There she sat with just a few strands of hair on her head and an external fixator on her leg that looked like a torture device. There were only 3 days until Christmas. I looked over onto the shelf in her room and there sat an "Elf on the Shelf" laying in a pretend bed and having a comparable external fixator on his pretend leg. The child's affected left leg was swollen with sutures and skin tenting up the imbedded pin sites that secured the fixator into the bone of her leg. She turned and looked at me smiling and said hello. I was aware that she wasn't feeling well that day but she told me she wanted to talk to me.

This child had the most beautiful smile and big brown eyes that looked right into my heart. When she spoke, she showed great expressions of heartfelt emotions. Following my introduction to her and her parents and a brief conversation with signing of consents, we began to talk. She loved the idea that she was able to choose her own pseudonym. Without hesitation, she said she wanted to be called Santa Claus because it was almost Christmas! She shared with me how her Elf on the Shelf had been magically moving everywhere at night while she was asleep! So much excitement was heard in her voice filled with imagination and unfiltered innocence. Her hands 
and her body were small but she didn't want help with her drawing but to do it by herself.

Santa Claus wanted to draw what she called the perfect nurse. She was extremely animated with this drawing. She did not want to be interrupted and told me she wanted to think. In the drawing, her imagination and level of cognitive maturity were exposed. She explained that she was in the drawing with her "Rainbow Dash" hat on which she told me clearly is her favorite character on the show "My Little Pony." As she was describing this to me she had her mother hold up her hat. Smiling, she explained that she drew a unicorn because a unicorn would be a perfect nurse. Looking into my eyes, she indisputably told me the reasons why she wanted a unicorn for a nurse. The unicorn had magical healing powers, the ability to fix everything, be gentle, remain quiet at night so she could sleep and not be interrupted, keep her busy with fun things to do and come quickly with pain medicine so she did not have to be in pain for long. WOW!!!! This little girl was 8 years old with an astounding imagination. She asked me if I could find a unicorn, could I ask the unicorn to be her nurse. I told her I would try. At her very young age, Santa Claus hoped for that person in her imagination that could take all of this pain and suffering and disease away. We spoke and her innocence and unmistakable inner beauty was overwhelmingly apparent. Through the eyes of this 8 year old child, truths about approachable nurses were heard. She wanted to take a picture with me while holding up her drawing so we did as long as she could wear one of her favorite character hats.

"Wolverine." Before speaking to this 9 year old little girl, I spoke to her mother on the phone. Her mother told me that Wolverine was diagnosed with non- 
Hodgkin's Lymphoma about 2 weeks before Christmas and when they told the child she was going to have to fight this, the child said, "I'm not going to fight this, I'm going to win this!"

When I walked into the room, I saw Wolverine sitting in her bed encircled by a very long caterpillar stuffed animal sectioned out with the colors of the rainbow. In her bed was also a stuffed smiley face pillow. There she sat in the center of a huge arrangement of bright colors. Wolverine was very thin and frail and with very little hair on her head. She wore her own two-piece pajamas that were red and blue with what looked like Star Wars designs. Later she told me she was a fan of Star Wars. It was immediately apparent that this young girl of 9 years had her own personality. I introduced myself to her and her aunt and mother and grandparents. Hanging in the room were countless drawings and handmade cards. Her central line was covered by her pajamas but hanging next to her were several bags of IV fluid and the cardiorespiratory monitor she was on. This child had no frills and pink or what could be described as "girly stuff."

Wolverine spoke directly to me, looking into my eyes and said hello with a pleasant smile. She told me she was 9 years old but very quickly followed that she would be 10 in February (next month). At the time I asked her to decide on her chosen pseudonym, she smiled and looked around and quickly responded with "Wolverine" as this was her favorite sports team. I began to think that this little girl may be more of the tomboy. Wolverine was intense with her comments on the nurse and focused mostly on the fact that she thinks nurses should tell the children in the hospital everything because they have the right to know. Knowledge, honesty and truthfulness 
were very important to her and she emphasized her age and her feeling that she was "grown up." While I was getting paper and crayons together for her drawing I noticed a clipboard on her bed with a sheet of paper on it and writing. On the paper was written "I am brave, I am awesome, I am strong" along with some other comments about feelings. I asked her to tell me about it and she told me that those were her thoughts and that she writes it down on paper to help her remember what she needs to do to stay strong and get through this. Wolverine drew a very simple picture of a nurse and wanted a mechanical pencil to try to make it as perfect as she could. She did not elaborate on the imaginative nurse but the real. Wolverine felt more comfortable as the time passed during our conversation as she allowed her mother to leave the room to speak with a visitor. As I spoke to her, the expressions on her face were intense and she definitely wanted to share with me her well thought out perceptions and feelings about how a nurse should act around and speak to hospitalized children. Wolverine was serene, serious and very reflective in her commentary yet smiled and established eye contact consistently throughout our conversation.

"Dan." I received a call from the nurse manager that there was a 10 year old boy from India who wanted to partake in my study. Walking into the Sunshine Clinic, I found him sitting in the waiting area with his IV pole and fluids running at a table talking with other children waiting for treatment. There sat a petite boy of small stature with darker skin and hair indicative of his culture. Dan was neatly dressed in a blue polo shirt and khaki pants and shoes. His dad was standing right by his side bringing him a container of healthy snacks to eat. I was introduced to both dad and 
Dan and together they smiled and we agreed to hold the interview in a private exam room. Dad helped Dan push his IV pole while Dan carried his snacks and his IPAD and we walked as a group into the room. After a brief conversation with both, Dad and Dan were very pleasant and signed the consents. When I asked this child what name he would like to choose as his pseudonym, he looked at his father and they both smiled. The child's dad looked at me and said that the child always wished his name was "Dan." So Dan it was, Dan had been given a name very indicative of his culture in India and he wished he had a more American name after living here for a while. Dad then left to go back into the waiting room to converse with the other parents.

There was Dan in the chair right across from me carefully eating his snacks and smiling, patiently waiting for me to start. I spoke to him for a few more minutes to be sure he felt comfortable in the room with me as his dad left. Dan used language that was very serene and profound. Dan used the word "tension" to describe anxiety and "big grin" to describe the smile. It was clear that this child was of high intellect and cognition based on his word choice and well thought out responses. Dan was relaxed and unaffected by our conversation as we spoke and he just continued to eat his grapes and cheese like a little old man and spoke to me. Having been diagnosed with leukemia in India, Dan was able to share with me a comparison of nursing here in relation to India as he had spent time in the hospital in both places. This child was very sweet and contemplative. He was very careful with his drawing, trying to make it as realistic as possible wanting to use pencil only. Dan was smart enough to know and tell me that there really is no perfect nurse so he chose not an imaginative nurse but a male nurse on the inpatient unit at Mercy Children's Hospital who has a great sense of 
humor and made him laugh. As we spoke of his drawing, he clearly told me that he understood the word approachable and then he chose to write the word "characteristics" next to his drawing listing the descriptors he felt were most important. He drew and spoke with a great sense of what he perceived as important behaviors for a pediatric nurse as he experienced some that were nontherapeutic in India. Dan wished for joy in the nurses and said this relieved his "tension" in the hospital and one of the descriptors he wrote next to his drawing was "the opposite of serious." Dan sat poised and was very polite, eating and speaking with manners and care. When we finished, Dan smiled and we walked together back to the waiting room. Dan's dad saw the two of us and quickly came to walk with us back to where he was sitting handling his son with the utmost care. There was no mention of Dan's mother and she was not present.

"Jayson." It is time now to meet the $4^{\text {th }}$ child interviewed. This 11 year old boy was referred to me from the Sunshine Clinic. I walked into the waiting room and saw Jayson sitting at the table with other pediatric hematology-oncology patients joyfully coloring and doing crafts. This boy was wearing a t-shirt and sweatpants with a wide brimmed hat. Jayson looked up and smiled at me with his pale complexion and freckles. His mother was with him but talking to other parents. I was introduced to both by the nurse manager in the Sunshine Clinic. Jayson took a break from coloring and immediately stood up and he walked with me into an exam room. He wanted to lead the way. Jayson was excited to show me that he knew this place well and where he was going. This was his territory. The boy's mother came with us and she was very accommodating and welcomed my interview. Jayson had jumped up onto the 
exam table and sat there with a smile. His mother and I told him that he didn't have to sit there because all we were doing was talking and coloring. Jayson laughed, jumped down and sat next to me in a chair. Following our brief conversation, Jayson's mother signed consent and then went back into the waiting room to converse with the other parents.

Jayson was not at all nervous, in fact, he actually seemed excited that we were going to talk and color. When I asked this child what he would like his pseudonym to be, he chose a name that rhymed with his real name as he bopped his head up and down saying both names a few times over in a happy way. Jayson was a very joyful child and eager to participate. He had no inhibitions in his expression of thoughts and perceptions. Jayson was very excited that I would be giving him a Target gift card at the end of the interview and suggested that I take it out and leave it on the table so that I would not forget to give it to him. This child is one of 6 children with a sibling having special needs so this gift card was a big deal to him. Jayson was very sweet and extremely sensitive when he spoke of his favorite nurse who reminded him of his grandmother who had passed away. He was very concerned about the feelings of children in the hospital as it was important for him to have nurses he could talk to and who listened to him. On a playful note, Jayson grew very excited when he told me in tremendous detail the favorite games he played with the nurses and his strategies for winning.

Jayson was diagnosed with leukemia when he was 9 years old and he was able to share sincerely the impact of the diagnosis, hospitalization and treatment, stating that he wrote a memoir for school about it. He told me that he thinks he was destined 
to have this disease to meet the people he has met, especially the nurses. Jayson drew a picture of not an imaginary nurse but his favorite nurse on the inpatient unit. He chose a female nurse who significantly impacted his ability to get through the difficult times in a positive manner. Jayson told me I should color with him and was very excited to tell me what he had to say so that we could help other kids. He was in no rush to finish the interview. This was the longest interview I conducted because Jayson was so animated and excited to tell me everything and draw his picture. He also wanted to take a picture with me and he insisted on helping to take a selfie of the 2 of us together with him holding his drawing. Jayson said if he was told he had to be admitted to the inpatient oncology unit at Mercy, his first expression would be woohoo!! He loves the nurses up there and they made him feel welcomed and happy. When we were done, Jayson went back to play with the other children and do arts and crafts. Going back to the clinic on another day to see another child to interview, I saw Jayson as he waved to me wearing his St. Patrick's Day hat, eating cupcakes and playing while getting his treatment. Jayson was a comfortable, fun loving child with great sincerity, a big beautiful smile and a love for life - happy all the time.

"Vladimir." Vladimir is a 12 year old boy being treated for T-cell Lymphoma. The meeting to interview was held in the Sunshine Clinic. When first walking into the clinic, I saw Vladimir sitting in the waiting room next to his mother. He was not sitting at a table with other children but close to his mom. This child was wearing a tshirt and sweatpants and a Providence College winter hat. It was obvious that he had no hair as his eyebrows and eyelashes were gone. Vladimir was protective of his hat, pulling it down over his ears. I was introduced to Vladimir and his mother by the 
nurse manager. Vladimir looked at me with a big beautiful smile displaying his prominent dimples but yet a bit timid and shy. We walked together into a private exam room where we would talk and the nurse would hook Vladimir up to his chemotherapy. Vladimir sat up on the exam table and the nurse started his therapy. This child chose to remain there as that was where he felt most comfortable. I sat in a chair across from Vladimir. Remaining in the room was his mother and the child's father who was also in the room but in and out on work phone calls. Casual conversation ensued with the parents and Vladimir for a few minutes before the interview began. Expressions of concern and descriptions of family life from Vladimir's mother made it clear that mom was very protective of her youngest of 4 children. When asking this child to choose his pseudonym, he looked quickly at his dad and they both smiled and the child immediately said he would like to be called Vladimir. There was no hesitation as the young boy was a fan of science fiction and computers along with his father and this was the name of a character he loved to impersonate and imitate at home. The parents and Vladimir laughed and enjoyed the ability to select this name. As I looked at Vladimir, I noted his sneakers that were unique filled with characters throughout. I commented about his sneakers, telling him how cool they were and asked him where he got them. Vladimir was very excited to tell me that he was able to order online providing the characters he liked and they were specially made with his favorite show themes.

Vladimir was insightful in his responses and yet quiet and shy. As I asked questions, he paused to think and then responded without difficulty but with great sincerity. Each time I would speak, he would look at me and then put his head down 
to think and then look up with a big smile and thoughtfully respond. Vladimir was not rushed but calmly spoke of his genuine perceptions of what makes a nurse approachable. This boy told me he was certain he knew what I meant when I used the word approachable. Vladimir was pensive and deep in his thinking. The comments made by Vladimir emphasized the importance of nurses who engaged with him in real conversations and who spoke to him as if they truly wanted to see him and were excited to hear what he had to say and listen to him. Vladimir seemed to be accepting of his diagnosis and treatment and trusting of the nurses while also knowing that his parents were there with him. Vladimir had a connection of comfort with his mother and what appeared to be one of fun and commonality with his father. Vladimir was quiet and calm. The interview was well thought out but not long. He wanted to make his point clear but accomplished this in a succinct and polite way.

“Carley." Arriving at the Sunshine Clinic, I was introduced to Carley. Carley is a 12 year old girl with relapsed Alveolar Rhabdomyosarcoma. This is a rare type of soft tissue cancer found in children with possible symptoms of severe muscle pain, swelling and/or the appearance of a growing lump. Carley was not in the waiting room but in the space where she would receive her chemotherapy treatment. As I walked in, no introduction was needed as I had met Carley and her mother previously as an inpatient. Carley was sitting in the reclining chair awaiting treatment. She was a very small, thin and frail young girl with leggings on and a long sleeve shirt. It was hard to believe she once played softball on her town league as her mom reported, because she was so fragile looking. She had very few strands of hair that stuck out of the hat she was wearing. On her head was a "love your melon" hat, a hat designed for 
children with cancer by Love your Melon Inc. which is an organization dedicated to giving a hat to every child battling cancer and supporting nonprofit organizations who fund pediatric oncology research and provide support for families of children with cancer. I said hello and Carley and her mom looked up and smiled at me in a subtle way. They were both pleasant and extremely cooperative and willing to talk to me but with a serene demeanor. Carley's mother was sitting in a chair next to her. Our conversation began and Carley's mom told me the path to her child's diagnosis. This was a situation where Carley was in severe leg pain and every time her mother brought her to the doctor or to the hospital, complaints were minimized and mother was told nothing was wrong. It was not until the mother demanded an MRI that this rare form of muscle cancer was diagnosed in Carley. Carley's mother looked tired and worn and her story revealed frustrations with the health care system as no one would listen to her concerns. This child has been treated for this diagnosis for 2 years and has now relapsed. Carley was quiet and reticent. She listened to our conversation reinforcing her mother's historic review of the past 2 years. Carley was in the chair reclining comfortably and on the floor laid her leg brace. I asked Carley to choose her pseudonym and she quickly said Carley because it was her favorite character on a Disney show. I commented on her hat and she told me she has 8 of them and wears them all the time because she doesn't like that she has no hair. We began the interview and Carley was very quiet and shy. She continually hesitated to respond, unsure of herself. There was not a free flow of feelings but a quiet sense of discomfort and insecurity. Carley did not appear to have a great deal of confidence in herself as she kept making negative comments about her inability to answer questions and even 
draw a picture. Continually, I reassured her and tried to create an environment with positive reinforcement and acceptance. Carley answered but often with a sway of her eyes and a shrug of her shoulders. When choosing a picture to draw, Carley did not draw an imaginative image but a realistic picture of a female nurse emphasizing the need for an approachable nurse to be smiling and happy. Carley said that she liked it when the nurses left notes on her board and came into her room and danced to the songs from the Lion King! As I spoke to Carley, I tried to maintain eye contact and show a real sense that she and her voice was important and mattered. Carley often looked down and at her mother attempting to think and gain support. Carley's mom said that when Carley speaks of the inpatient unit and the nurses, she says "it's like her second home." Seeing other small children coming in to receive treatment, Carley being concerned, wanted to make them something to help them to stop crying and not be afraid.

“Hobbs." Walking onto the inpatient oncology unit, I met Hobbs and her mother. Hobbs is a 12 year old girl diagnosed with osteogenic sarcoma about 2 years ago. As I walked into the room, I laid my eyes on a young girl lying in the hospital bed with no hair on her face or her head and a moon face from the medications. There, to the right of her bed in the cubby stood her prosthesis. Because of the severity of this bone cancer, it was required that her affected leg be amputated, a heartless treatment for anyone to endure, but especially for a pre-adolescent girl. Even with amputation and aggressive treatment, she had relapsed and her only hope now would be experimental treatments. Entering, I said hello and introduced myself to Hobbs and her mother. This was my second attempt to speak with Hobbs as the first 
time she was occupied with the volunteer woman the children call "the reading lady" who would sit and read books to the children in the hospital. Hobbs was resting but opened her eyes, looked at me and smiled, saying hello. Looking at her, I saw a beautiful girl with a magnificent smile who seemed warm, welcoming and a bit angelic. It was amazing that this child could smile and be happy with all she has been through and her current poor state of health. Her mom was pleasant and accommodating, signing consent and agreeable to the conversation. Mom remained in the room. Hobbs had not been feeling well but she did not want medications that would make her sleepy because she wanted to speak with me and be alert and awake. Forfeiting her ill feelings, she opted to have the interview first. Hobbs told me she was half Japanese and the other half was "a bunch of stuff." She found her heritage a fun guessing game to play with the nurses. She put on her glasses and we had a brief conversation before beginning the interview. Hobbs was warm, kind and very thoughtful. She was innocent and unpretentious. The information she shared was unfiltered. There were times during the interview that her deep and serious responses could bring on tears as she spoke of her feelings of loneliness and fear and other moments where Hobbs would be laughing and funny with imitations and made-up descriptions of nurses and doctors. She mimicked a student nurse who she said just "tried too hard to be happy" and called the interns "baby doctors." Hobbs had quite the personality enjoying the humor that often comes with the truth. When I asked Hobbs to choose her pseudonym, she took a moment and thought to herself and responded with "Hobbs" as this is a fictional comic character that amused her from the cartoon Calvin and Hobbs. This child seemed deep in her thoughts based on the cruel and 
merciless disease and treatments she has tolerated. Hobbs was calm and expressive, finding it very important to share her perceptions. She had been hospitalized and rehospitalized on countless occasions. As she spoke, I listened carefully and she looked into my eyes and tried desperately to share her thoughts with me. Hobbs was in no rush and she seemed to enjoy the conversation. Talking with Hobbs was effortless. As we began the drawing, Hobbs was actively engaged, having a drawing table and carefully selecting her crayons. This drawing was not imaginative but very realistic and colorful. She was creating what in her mind constituted a perfect nurse based on appearance and behavior. Hobbs was very sweet and she had a strong desire to try to please others, but at the same time, hoped nurses could know how she feels inside. Hobbs spoke of her love for "Goodnight Lights Mercy" as this helped her to know that people in the city knew she was there and took away some of her loneliness.

"Goodnight Lights Mercy" is a local tradition in Southern New England City that was created about a year ago by a gentleman cartoonist, to exchange signs of flashing lights to say goodnight to the children at Mercy Children's Hospital. At 8:30pm every night, children flash lights from their hospital rooms in response to the flashing lights of residents, businesses and any others in the city. Hobbs found that flashing her lights with the nurses created recognition that people knew she was there and cared enough to say goodnight to her. She participated fully thinking through all of her answers before responding. As she lay there, Hobbs seemed to have a sense of acceptance and peace about her. Hobbs was both funny and serene providing insightful information from her experiences. 


\section{Perceptions of Approachable Nurses}

As noted earlier, the purpose of this research study was to explore the perceptions of school-age children with cancer related to the approachability of hospital nurses. The specific research questions focused first on gaining information regarding children's perceptions of nurses who they think and feel are approachable; secondly on obtaining information about how the children describe the characteristics and behaviors of the nurses, and lastly the children's comments regarding the impact of having nurses who are approachable during their hospitalization. During the interviews, the children based the characteristics and behaviors of approachable nurses within the context of their perceptions of nurses who are approachable.

As is apparent in the above profiles, each child had a distinct personality, way of speaking and individual family context. At the same time, all of the children seemed to expect that nurses who were approachable and easy to talk to, would approach them regularly. Hobbs mentioned that "the nurses here, they do it a lot, to check in on you and make sure you are doing okay" and understand that "sometimes you feel lonely because you want to go home even though you know that there is people around you." The children seemed to feel as though the nurses who came into their room, cared and took the time to know them. Vladimir said "like whenever he sees us, he'll talk to us and we'll have conversations and when we get admitted, he'll usually, even if he is not our nurse, come from a different pod and stop by to say hi." On this unit, many of the children remain in their rooms because of neutropenic precautions or because they are receiving infusions of chemotherapy and may not feel well. The children seem to have a strong reliance on the nurses to come and approach 
them, making sure all of their needs are met. The children speak of the nurses who are easiest to talk to as those who often approach them.

By approaching the child, the nurse, through the eyes of the child, makes the effort to know them. The idea of a nurse taking the time to know and understand the child was highly related to being easy to talk to and approach. Jayson said "they should always know how the kid is feeling. If the kid is feeling sad, they can help with that. If the kid is happy, they could play a game with them. That's what I would do, that's what I would want." Wolverine spoke of familiar nurses she found most approachable as "easiest to talk to because sometimes I know them more than other nurses. Like I know what they are like more than other nurses." Santa Claus said the nurses "should know if the child feels scared" and Hobbs followed with the comment that nurses should know "children are not always happy even if they look happy...Like you might not feel good but you try to like not, not feel good even when you have the medicines that are going to try to help you feel better." These children expect the nurses to anticipate and know the needs and feelings of the hospitalized child because of time spent to understand verbal and nonverbal cues.

The children seemed to see the environment of this inpatient unit as one of cheer and optimism. The researcher noted the mood to be clearly upbeat as there are often clowns singing and therapy dogs coming to visit the children. The children enjoyed the availability of the child life therapist to provide activities and events to engage them in. The researcher, in agreement with the children interviewed, often found the nurses on this unit to have positive attitudes and attempt in every way to create a culture of caring and fun with laughter, jokes and lighthearted humor and 
attire when appropriate. Dan commented "the nurses here smile and make me feel like the hospital is like my home." Jayson and Carley mentioned that the nurses on the unit were like their "second family" with Jayson elaborating with "I felt welcomed there. I felt like I was destined to go there." The children often used the term "feeling comfortable" while in the hospital and attributed this relaxed mood to the environment and culture of the unit established by the nurses.

Nurses are "nice." The children perceived the nurses who were "really nice" as easiest to talk to. The word "nice" was used on multiple occasions by each child. Santa Claus stated "the easiest to talk to nurses are the ones who are really, really nice." She added that what makes these nurses nice is because "they tell me what they are doing" and mentioned specifically that one nurse in particular was "really nice and funny so that is why I think it makes it easier to talk to her.” When I asked Santa Claus to elaborate on what she meant by nice, she said that "nice nurses should smile" and know that children "might be scared if they are doing something for the first time" and should "talk kindly."

When speaking to Wolverine about the use of the word "nice" when first meeting with her favorite nurses, she said "I thought they looked nice because they had a smile on their face." She also commented that nurses who are "all so nice, help me calm down and talk to me in a calming way." When home and needing to return to the hospital, Wolverine wonders "are the nurses going to be as nice as you think?" Dan stated immediately that the nurses "are all nice" because "they make me feel comfortable" and "give me board games to play to make it fun and then I don't have to think about what is going on." This child also reported "they are so nice because they 
are easy to talk to when I was scared and losing my hair." Dan described nice nurses as those who "make me happy and tell me it's going to be okay and that I will be okay." The nice nurses were identified as those who are "funny all the time, kind to me and so I can feel relaxed like I am at home." Dan said also that "nice nurses are kind and you feel comfortable because they are smiling and happy."

Exploring the meaning of the word "nice" gleaned a great deal of meaningful content related to children's perceptions of approachable nurses. Jayson described the nurses as "really nice" and when asking him to explain, he said "I think it was the way they acted" and "they would always smile, never frown. They were just always happy" and "that made me feel welcomed and happy." When asking him what he thought about when he was home about the hospital stay he said he thought about "how nice the nurses are." Jayson singled out one nurse in particular who was "really nice" because she would "take time to play some games" with him and "talk to him." The perception of this child was that "nice nurses should know how the child is feeling every single day" and he wouldn't mind going back if he had to because "the nurses were all really nice." In speaking to Vladimir, his first description of the nurses was that

They are always nice. They always talk about, they would always ask questions about what you would like to know, they would talk about it with you about what they were doing everything too so it wasn't like silent. Because it's kind of weird like when it was just silent when they did everything and all you could do was watch what they were doing and you didn't know anything that was happening. 
When Vladimir first met his favorite nurse he said "he was like a person that you see and he was very happy and everything and was very nice and wants to talk to you like right away and starts conversations and who I thought might be easier cause he's a guy and he might have similar stuff too." When drawing his picture of the approachable nurse, Vladimir described the facial expression as "he's smiling. He's really joyful and nice and it's easier to talk to him and he looks happy so it's not like a sad place. It's a little happier place to be." When home, he thought "mostly about the nurses. Like the nurses who talked and everything and that were nice."

Carley described her ideal nurse and said the nurse should "be nice and approachable" by "like smile and stuff and leave little notes on my board" and "be nice to the kids and parents" by "getting them the things they need." Vladimir and Carley both mentioned the need for nurses to help both the child and the parents while hospitalized, meeting the needs of the whole family. Hobbs used the word "nice" and said "if you need something done, they will do it for you" and in relation to her favorite nurse she said "she was just nice and since I was kinda scared, she made me feel a lot better." When at home and needing to return to the hospital, Hobbs said "when I know I have to come to the hospital I am not really happy about it because I don't get to be at home but there is more good things about Mercy than not good things because the nurses are nice." Her thoughts about the hospital are about "the nurses because they are so nice" and "they are funny." The perceptions of the approachable nurses revolved heavily around the meaning of the word "nice."

Nurses are "smiling and happy." From the voice of every child interviewed came the declaration that an approachable nurse is always "smiling and happy." The 
smile, happy face and demeanor welcomed every child to interact. Six of the seven children said that the first time they met their favorite nurses, they remembered them as "smiling and happy." Jayson summed this feeling up well as he said "They would always smile. Always. They were never sad. They never frowned. They were just always happy. That made me feel welcomed and happy to be here." When discussing her drawing of the perfect nurse who is easiest to talk to Wolverine said "I like to see people with a smile on their face all the time. It makes me feel more comfortable to talk to them and that's what I feel." Of the seven drawings, six drew a nurse with a smile. Dan was able to express "I think when a person is smiling, you feel less tense and scared. It makes it easier to talk to them because they seem happy." The children were asked to describe how a nurse should act and behave with children in the hospital. Vladimir responded that "always having a smile helps make the kids happier...so it's not like a sad place." Carley and Jayson thought "nurses should always smile and be happy" because as Dan and Wolverine said "when somebody has a smile on their face, then you can be a little more relaxed" and "you feel comfortable when the nurse is smiling and happy." Wolverine was able to identify the importance of the child smiling also as the interaction is reciprocal and believes the nurses will be more likely to smile if the child is happy. When asking her if it is difficult for her to always be smiling she said "sometimes it's hard," acknowledging the fact that it is hard to continually be happy. When she is home, Hobbs thinks about the nurses because they are always happy. Hobbs noted that the smile needs to be authentic as she described a student nurse "she would try to be too happy and perky and it kinda got a little annoying after a while. They should just be themselves... and not smile all 
the time because that's annoying." Clearly, these children are more likely to approach a nurse who is smiling and happy as they describe this as an open invitation to interact.

Nurses are playful. The seven interviewed expressed the feeling of great joy in the hospital when the nurses were "fun and funny" and found these nurses easy to approach. The children described the nurses as often telling jokes, "pulling pranks" or just having fun. Often the children said they forgot that they were in the hospital when they were having fun and laughing. Without a doubt, the laughter lessened the tension and made the children feel welcome and at ease, one even said he felt "at home." Wolverine said that when the nurses make things fun and easier to do like taking medicines it "makes me feel like they care a lot and they want to help you take the medicine." Wolverine, Jayson, Dan, Carley and Hobbs spoke of one of the nurses on the inpatient unit who was always funny and made them feel comfortable and happy. Wolverine said "He makes me feel the most comfortable because he's funny. He makes me feel good inside." Jayson and Hobbs recalled how this nurse allows them to squirt him with needless syringes filled with water. Jayson said "He's funny. He would sometimes come in with a syringe with water and squirt it but not at me so I had got a syringe with water and squirted it at him. He was just so funny. He makes me laugh and feel comfortable." Dan drew a picture of this nurse as his favorite and said "He has a big grin and is always happy and funny. I think the perfect nurse should be kind, funny, friendly and the opposite of serious." These children reported feeling most relaxed around nurses who had a sense of humor and found them easiest to talk to. Santa Claus said "I like funny people. I don't like people that are kind of boring and they don't really do much stuff and they are kind of grumpy." Vladimir 
spoke of another nurse who "would tell stories that are funny" and "his stories were funny and made us smile a lot" while Carley liked "fun nurses" who "usually danced to the Lion King songs" in her room. Hobbs remembered fun in the garden outside when she had "water gun fights on a nice day" and when she sees a nurse walk in with a smile and colorful scrubs with patterns, she thinks to herself "They are fun."

Without a doubt, these children perceived nurses who have a sense of humor and bring laughter, fun and play into their hospital day as those who successfully diminish tension and enable approachability, comfort and conversation.

Nurses "talk and listen." The children reported that they want nurses to tell them what they are doing before they are doing it and while it is taking place. Explanation in terms these school age children could understand took away the fear of the unexpected and empowered them with simple knowledge of what was happening to their bodies. Talking and listening to the child helped to establish a relationship and showed genuine concern that the nurse cared and wanted to help. The children found nurses most approachable who were able to speak in a "calming way," were not rushed but in control. Dan reported that when nurses are easy to talk to, they "lessen the tension and make me less scared." Vladimir reported that conversations especially during procedures "don't make it so awkward and help me forget what is happening." Vladimir along with Dan and Jayson appreciated the diversion created with dialogue. Taking the time to talk to the child helps the nurses to "know how the child feels every day so that they can help them and not let them be scared." It is clear that fear and anxiety were prevalent in the lives of these hospitalized children and the nurses had a pivotal role in decreasing these fears. 
The children seemed to get a sense that when the nurses took the time to listen to them and "really show they care" by helping with the little things, they felt the nurses truly understood them and how they felt. The children enjoyed talking to nurses with similar interests. As Vladimir said "it is nice to talk to a nurse who has things in common with me." This created a bond and a connection with the nurse. Hobbs enjoyed time talking to the nurses because she said it made her feel less lonely and when the nurses talked to her it made her "feel good inside because I am not just their patient, I can talk to them. I am not just a kid in the hospital. I am someone. I can talk to them and they can talk to me." Jayson and Dan spoke of time spent playing a game or just talking with their favorite nurse because they were able to share things that bothered them like losing his hair. Vladimir also mentioned that he felt that gender made a difference and he found it easier to talk to a male nurse because he could understand him. This was the only child interviewed that mentioned gender as a factor in approachability. An approachable nurse was also one who the children reported was genuinely happy to talk to them and see them. Vladimir said about his favorite nurse "he'll talk to us and we'll have conversations and when we get admitted, he'll usually, even if he's not our nurse, come from a different pod to say hi." There is no question that these children could sense the difference between someone who truly exhibits concern versus another who is there just to do the job. Santa Claus said “I certainly don't need any nurses coming in that don't really feel like coming in."

Nurses are creative and competent. Appearance was mentioned by a few children who found that colorful scrubs and clogs invited interaction with a nurse. 
Vladimir said "When they are wearing scrubs, I like pictures on it because it shows you a little about them and what they like in their clothes and this is the type of person who would go up to you and start a conversation... that makes them approachable." For Hobbs, when she sees a nurse who is wearing colorful scrubs with patterns and clogs with prints, she thinks right away "that they are fun." Santa Claus found when the nurse brought her a popsicle, it was welcoming. Nurses who were able to divert the attention of the child while talking, playing games or introducing an IPAD during a procedure "made the tough times easier." Jayson spoke of the "little things" his favorite nurse did to creatively help him. He spoke of hitting his port-a-cath needle into his lunch tray and this nurse took the time to create "a blocker so that when I bumped it, it wouldn't push my needle and I decorated it because I love to do artsy stuff." This same nurse helped Jayson to create a soft bird's nest with his lost hair for the baby owls in his backyard. Nurses who showed they cared by going above and beyond the tasks to complete in a shift were most approachable and easiest to talk to.

While hospitalized it was important to all of these children that nurses understand that the child does not want to be in pain so they need to answer call lights and "get the pain medicine fast." Santa Claus described her drawing of the perfect nurse, an imaginative unicorn, as one "who can fly so it can get stuff like medicine really fast." The children could perceive when a nurse was competent and confident in care and this made that nurse desirable and the child feel safe and well cared for. Carley said she felt safe with the nurse who was able to help her quickly when she was having an allergic reaction to a platelet transfusion and couldn't breathe and then another who she described as "a very good nurse... doing everything perfect for her 
patients." Dan was able to acknowledge the importance of competence as he was affected by the lack of it while in the emergency room and said "the only problem with the port is when you go to the ER and I have a new nurse who does not know how to access it. That is a problem." Dan also said the approachable nurse reassures the child that "they will be okay" when they are scared. The perceptions of these children revealed significant insight and a great awareness that they observed, understood and have a voice.

\section{Impact of Approachability}

Based on the children interviewed in this study, both the verbal and nonverbal communication of the nurses directly affected the child's perceptions of approachability along with the fear, anxiety and psychological impact of events during hospitalization. While home, these children reported a frequent recall of the way in which the nurses behaved and treated them. Upon knowledge of readmission, all of these children immediately reported thinking of the nurses.

Knowledge/Knowing. Throughout the interviews, the children voiced how important knowledge was in decreasing their fears of the unknown. Clearly, all of the children felt vulnerable and wanted to know what was happening to their bodies. The children's feelings of a loss of control and not knowing what was going to happen seemed to cause extreme fear. For example, Santa Claus said "I like to know everything that is happening but sometimes they don't tell me what is happening and I don't like that." Wolverine was very intent on the importance of telling children the truth and she did not like surprises otherwise she said she "wouldn't know what to expect." "I feel the nurse should know that the patient is ready to hear what they have 
to say sometimes and sometimes the patient isn't ready" and "when the nurses tell me what is going on and when everything is going to happen I felt less scared.” Dan said that "the nurses make me feel comfortable because they tell me what is happening and I don't need to be afraid but of course, you are always a little afraid." Vladimir found that knowing helped him to understand and said "When you've been here a couple of times, you are not nervous that much because you know usually what's going to happen and also sometimes you are nervous so it's easier when they tell you what they are doing so you are not as nervous when it's happening and you're not confused as to what is happening too." Vladimir and Carley also commented that when they knew what to expect and what was happening, they were less scared and anxious. Fear and procedural anxiety were ameliorated when the children were given explanations that were sincere.

Talking and listening. All of the children reported that when the nurses took the time to talk to them and listen to their worries, they felt a sense of genuine concern. Because these children are too young to make independent decisions about their health care, Wolverine in particular was fearful that she would be pushed aside because it may be assumed that she would not understand. She said "I want to know what is going on, not just my parents know what's going on, and the nurses need to tell me the truth for everything." The tone of speech was important to all of these children. Santa Claus said the nurses should "talk kindly" and Wolverine said "they help calm me down because they talk to me in a calming way." The manner of speech of the nurses tended to set a relaxed tone and a mood of comfort. Dan said that when they "tell me it's going to be okay and I will be okay, this helps to lessen the tension 
for me and it's not so stressful."

Having conversations and engaging with a child, gave the child a sense that they were being understood and created an aura of friendship. Vladimir said "I know like the nurses that usually give me the medicine like whenever we come in and they say hi and when I know the people who are doing anything and they also know some stuff about me, they have conversations with me that aren't awkward and everything" and this "makes the nurse seem more like a friend than a nurse." By taking the time to talk to these children, the impact of distraction was mentioned by Vladimir as he said "they can come in and tell you what they are doing and also have a conversation so it's easier because you are not focusing on what is happening, you are more focused on the conversation and more about the happier stuff and not the medicine and stuff." Carley mentioned the use of distraction as the nurse spoke to her and gave her an IPAD to focus on as her port-a-cath was being accessed. Wolverine said that when the nurses took the time to talk and listen to her, it allowed her to cooperate and complete a procedure in a manner that was not rushed and in a way that she could tolerate.

Jayson elaborated on his favorite nurse as someone who took the time to listen and talk to him especially when he was going through "tough times" as he expressed, "this showed me that she really cared." Hobbs spoke of loneliness in the hospital and the impact of the nurses coming into her room and talking to her. She said "the nurses here, they do it a lot, to check in on you and make sure you are doing okay" because "sometimes you feel lonely because you want to go home even though you know that there is people around you." Also, "if the nurses can just come in and talk to you" they could know that the children "are not always happy even if they look happy." 
The time spent talking and listening to these children, clearly is important to be able to understand the concerns, fears and feelings of these inpatient children. By hearing their voices and responding to their needs, these children gain a sense of security that significantly impacts their sense of personal worth.

Fun and humor. In the midst of a difficult and challenging circumstance, all of these children expressed the positive impact of fun and laughter while hospitalized. Santa Claus, in comparing her analogy of the perfect nurse to a unicorn, described the unicorn as having magical powers so that "if I am bored, it can use its magic to like entertain me with something." Wolverine talked about the nurses as "funny and caring, they just want you to be happy all the time so when there is not such great news that you don't want to hear, they make it easier to talk about" and when she goes home and is told she has to return, Wolverine wonders "will the nurses be as fun as I think?" Vladimir talked about his favorite nurse, "his stories were funny and everything so it made us smile a lot and forget I was in the hospital.” When he is home, Dan said "I think of the nurses and the fun things I got to do in the hospital." The children recalled the fun they had with nurses when they were at home and upon notice of return. Most of the children remembered fun events that took place at the hospital particularly with the nurses who made them laugh, told jokes, allowed them to squirt water in needless syringes at them, danced in their rooms, played games and just made them happy. Jayson, Vladimir, Hobbs, Wolverine and Dan all mentioned the level of comfort they felt and the way in which it made the hospital feel like home. When Jayson was asked how he would feel if he had to return to the hospital he said “woohoo!! Because I get to see them all again!” Hobbs said "when I know I have to 
come to the hospital, I am not really happy about it because I don't get to be at home, but there is more good things about Mercy than not good things because the nurses are nice and fun." All of these children said that the procedures, along with taking unwanted medicine, were tolerated because of the fun the nurses created around the process. By creating an environment of comfort and joy, these children are less fearful during their hospital stay and the return visits are not quite as daunting knowing the nurses will foster fun and laughter.

Creativity and competence. When the nurses displayed creative ways to care for all of these children, a lasting impact of gratitude was created. Discussing the ways in which these children recalled the nurses who were most approachable, Jayson remembered hitting into the bedside table with his port-a-cath needle and feeling pain. He said, "The nurse had an amazing idea to make a blocker so that when I bumped it, it wouldn't push my needle and she made one for me and I decorated it...so then I wouldn't bump it again and it wouldn't hurt me." "She also had an amazing idea when I started losing my hair. My hair was so soft and we told her we had an eastern screech owl in our backyard that was living in one of our trees and she said that while I was losing my hair, we could keep it to make a nest for the owl babies. It made me feel better about losing my hair." Hobbs appreciated the nurses who were able to carry out procedures during the night creatively without waking her up. She said "Sometimes they take my blood, I don't feel it, because they do it really slowly and they don't poke and grab." Creatively making hospital experiences, treatments and side effects tolerable left a lasting impact on all of these children.

The impact of a competent nurse revealed a feeling of safety for all of these 
children. Carley recalled an experience of anaphylaxis with a platelet transfusion and said "I feel very safe with him because once I had an allergic reaction and he had to stick me with the needle thing and I was able to start breathing again." Vladimir reported no concern when he came to the hospital for treatment with the nurses as he said "I don't really worry about anything cause its mostly like the same thing and if it was something new, I don't really worry about it either cause it's just medicine that is going to help." This child expressed confidence in the competence of the nurses and the treatment. Hobbs relayed her faith in the nurses' abilities as she said "The nurses help me and when you don't feel good, they give you something to make you feel better." The assurance of a competent nurse provided 3 of these children, all aged 12 years, with a sense of being safe and well taken care of.

Attire. Two of the seven children, both age 12 years reported that a nurse's attire impacted the approachability of the nurse. Vladimir said "When they are wearing scrubs, I like pictures on it because it shows you a little about them and what they like in their clothes and this person is the type of person who would go up to you and start a conversation about what you liked even if they didn't know a lot about it. That makes them approachable." This child felt the presence of pictures on scrubs would help initiate conversation and create a sense of openness to shared ideas. Hobbs said "I like different color clogs" and she described the approachable nurse in her drawing as wearing her favorite color blue clogs and blue and green polka dots on her scrubs. She said when a nurse is wearing scrubs with different patterns; it makes her think immediately "that they are fun." She also drew a purple flower on the nurse's stethoscope because she said her favorite nurse wears this and when nurses 
wear certain trinkets or specific scrubs/clogs "it kinda reminds me of who they are." The impact of attire to these two children created an immediate openness and avenue to conversation.

Based on the perceptions of these children, the approachability of the nurse has a substantial impact on current and future hospitalization experiences. The interviews brought forth the importance of verbal and nonverbal communication. These hospitalized children are placed in a world with unknown health care providers and with a diagnosis filled with heartless treatments and side effects. The manner in which the nurses interact with, treat and behave while caring for these children, based on the above perceptions, carried impact related to anxiety, fear and stress and the creation of a relaxed environment conducive to comfort, acceptance and concern with respect for every child.

\section{Discussion}

Similar to earlier studies on the communication between pediatric nurses and children, the children in this study wanted to be heard and they were able to describe and reflect on their experiences with nurses in a hospital setting. The findings added further empirical support of the legitimacy of characteristics and behaviors of approachable nurses in a natural setting from the perspective of children.

Furthermore, the findings added new knowledge related to the impact of approachable nurses which affected the ability of hospitalized children to cope with fear and anxiety, creating a feeling of being at home during their hospital stay. Children want to be heard and approachable nurses have a significant impact on the ability of the patient to cope and endure the hospital stay with a positive outcome. 
Three major points of discussion will be developed in this section regarding the concept of approachability, the descriptors that surround this concept and the impact of the approachable nurse. The finding that happy faces are associated with approachable people adds further empirical support to the results of Campbell et al.(2010), Miles (2009), Willis et al., (2011), and Willis et al. (2013) and extends its scope to go beyond the lab setting to a natural setting on a pediatric oncology inpatient unit with children rather than an adult population. Additionally, all of the children had actually made contact with approachable nurses and agreed that nurses who are happy are approachable. These children were not presented with photos but based judgement decisions on the behaviors and appearance of the nurses who cared for them.

In earlier research, Willis et al. (2011) had determined that facial expressions were most significant when adults judged the approachability of another person. Researchers compared body language to that of facial expressions and determined that when the adult subjects were presented with the decision of who to approach, the judgement was made primarily on the nonverbal cues of the face as opposed to remaining body language. Similarly, the hospitalized children interviewed in this study noted the smile on the face of the nurse as one of the most important indicators that created a feeling of comfort and openness to conversation.

In retrospect of the initial concept analysis that was completed based on the method developed by Wilson, a similar expansion of characteristics arose. The findings lend empirical support to the initial theoretical definition of the concept of approachability. As the model cases were presented, it was found that the 
approachable nurses had a personality that was genuine and sincere. These nurses were both verbally and nonverbally welcoming, engaging with children in a developmentally appropriate manner. In conversation, there was a dynamic relationship wherein one did not overpower the other. Each of the model nurses seemed to connect with the hospitalized children in their own unique way whether it be playful or quiet. These nurses smiled often and offered themselves in a nonthreatening manner. Within the development of a definition for the concept of approachable from this concept analysis, approachable nurses were those that were open and receptive, took time to listen to the children and developed a relationship wherein knowledge was shared appropriately.

This definition highly aligns with the characteristics and perceptions provided by all of the children in this study. These children, as noted by Hobbs, Vladimir and Jayson identified the nurse who was easiest to talk to as one who showed genuine concern and was able to "be themselves." These children expected regular engagement as the nurses "checked in on them often," "left notes on their white boards" and came in frequently to talk even if they were not their patients. In conversation, all of the children expected to be listened to and included with a voice in all discussions. Approachable nurses were described by children in different ways as funny and competent and "amazing" establishing the perception that many different nurses with different personalities were all approachable in their own distinctive way. As Hobbs described "not scary," the descriptions provided by the children interviewed cited a nurse who was kind and open in a non-threatening way.

Descriptors derived from the literature were similar to those identified by the 
children in this study adding further support to characteristics of an approachable nurse. In 2007, Pelander et al., found that children described nurses who were kind and cheerful as easiest to talk to, similar to the comment by Santa Claus who said nurses should "talk kindly". "Friendly" was a characteristic that Campbell, O'Malley, Watson, Carlwood, and Lowson identified in 2000 which aligned with "nice, friendly and humorous" as sited by the children in the study by Lambert et al. in 2008. Both Jayson and Dan described approachable nurses as "friendly" and the use of "nice" was unanimously used by all of the children in this study. The terms "fun and funny" were also common within the children interviewed in regards to nurses who were easy to talk to. Pelander (2007) brought forth the characteristics of "gentle, patient and supportive." Santa Claus, in her drawing of the unicorn as the perfect nurse, described being "gentle" as an attribute, while Wolverine expressed the need for the nurse to be patient while giving the child time to take medications and calm down so not to be rushed. Jayson described his favorite nurse as supporting him "through the tough times." In 2012, Coyne and Kirwan recognized similar characteristics of "nice, kind, gentle, caring and funny" along with being a good listener and responding to requests for help and call lights as significant factors that children found important in a nurse while hospitalized. Hobbs, Wolverine and Santa Claus mentioned the importance of responding as quickly as possible to call lights and the need for pain medication. While these researchers attempted to speak with children in the hospital regarding the experience and need to be heard, this research affirms many of the characteristics identified and focuses primarily on the perceptions of the children related to their judgement of an approachable nurse. 
The impact of having an approachable nurse was described and found to be noteworthy by previous researchers and within the information gathered throughout this study. Previous researchers found that children who were left out of decision making, felt ignored, suppressed and powerless (Coyne \& Gallagher, 2011; Livesley \& Long, 2013). Every child interviewed in this study felt that when the nurses told them what was happening and going to happen, they felt prepared and knew what to expect. Lack of information and disregard would create a lack of self-worth and loss of control. Anxiety and fear were greatly modified with information and inclusion. The knowledge given to these children was said by Dan to "lessen the tension" and the children said that knowing prevented them from being scared and worrying about what was about to take place. The impact of being included in conversations enabled a feeling of worth and respect in these children as was also identified by Lambert et al. in 2008.

Pena and Juan in 2011 found that personal stories told by nurses became a useful means of distraction and aided in the elimination of stress in an anxious situation. Further empirical support was provided from the reports of these children. Vladimir clearly stated that when he was having conversations with nurses, he "forgot he was in the hospital." Wolverine, Jayson, Dan, Carley and Hobbs spoke of the importance of talking to the nurses and how the storytelling and dialogue developed more of a friendship and created an environment that enabled a feeling of being comfortable that resembled "home." The children in this study felt "welcomed" because of the relationships that developed based on discussions. These children reported that knowing the nurses, created less anxiety upon knowledge of a return 
hospital stay.

The interviews conducted brought forth noteworthy information that will add to the breadth and depth of knowledge related to the effects of communication between the pediatric oncology patient and the nurse in the hospital. The findings of this study have further developed the concept of approachability and identified descriptors surrounding the creation of a definition and the impact of the approachable nurse on hospitalized children both inpatient and at home following an inpatient stay. Previous work, although minimal, aligns with the responses of the children interviewed. The data collected in this study supports previous findings and contributes to the literature. This study contributed to nursing knowledge in the practice domain. The voices of these children provided rich and meaningful information in relation their judgement of the approachable nurse, therefore useful for improving practice. Several factors were illuminated by the ability of these children to magnify the importance of therapeutic communication and the impact of having an approachable nurse to create an environment wherein children can receive care in a non-threatening and compassionate manner. 


\section{Chapter 5: Summary, Conclusions and Implications}

The purpose of this study was to obtain a description of the characteristics, behaviors, and potential impact of nurses who school age children perceive as approachable on an inpatient pediatric oncology unit. Based on the international treaty developed at the Convention on the Rights of the Child in 1989, it is the obligation of all, including health care providers to allow the voice of the child to be heard to enable respect and uphold dignity. This along with the clinical observations of the researcher became the driving force behind this study.

In the review of the literature, the author identified three bodies of work in relation to the concept of approachability. The initial array of studies revolved around the psychological research on approachability. Psychologists explored the way in which adults, placed in a controlled laboratory setting, would decide whether or not they would approach another person. They presented adults with a situation and then with a standardized picture of a person with different facial expressions and body language. These researchers identified and labeled a concept that they referred to as the judgement to approach from the perception of adults in a controlled environment. Work focused mainly on facial expressions including those with happy, angry or neutral expressions (Campbell et al., 2010; Miles, 2009; Willis et al., 2013; Willis et al., 2011). A primary finding was that happy faces were consistently associated and identified with a person being approachable. Willis et al. (2011) focused on the difference between facial and body movement noting that facial expressions were identified by subjects as more significant when judging approachability. In another study, Miles (2009) found that a smiling female was seen as more approachable than a 
smiling male. These researchers sought to explain the conditions surrounding approachability but did not define the concept.

Within the context of the hybrid model of concept development, a Wilsonian concept analysis of approachability was completed by the author in relation to the pediatric nurses. The goal of this analysis was to extract characteristics of the approachable pediatric nurse to help in forming a definition of the concept. Within this analysis, two model cases were presented along with one contrasting case. Following a description of each, the author was able to identify characteristics to create a working definition of an approachable nurse as one who is both verbally and nonverbally welcoming; willing to receive another in a dynamic relationship wherein one does not overpower the other; able to share information with the children appropriately; connotes a feeling of receptiveness to another without reservation or hesitation based on uniquely individual behavior that is both spontaneous and purposeful. Noteworthy, it was found that the behaviors of these nurses were sincere and genuine to the personality of the particular individual. Important terms in this definition include behaviors of the approachable nurses that were both verbally and nonverbally engaging and age appropriate for the developmental needs of the child. Additionally, these nurses were able to connect in their own way with children whether it be in a playful or quiet manner.

Nurse researchers, primarily in Europe, had begun to explore the experiences of children in general in hospitals. They were able to describe both the positive effects of good communication between pediatric patients and what appeared to be approachable nurses and the negative consequences that ensue when seemingly unapproachable 
nurses created an environment wherein comfort and therapeutic communication did not exist, although the concept of approachability was not used. These authors explored the experience of hospitalization. In order to communicate effectively, researchers revealed that, based on implicitly identified verbal and nonverbal behaviors, a nurse who is easy to talk to, fosters the establishment of the nurse-patient relationship. This research was particularly noteworthy as a major first step in responding to the needs raised within the international treaty to foster the voice of the child while also drawing attention to the importance of nurses who are approachable.

In review of the psychological literature, concept analysis and nursing research, a clear gap appeared in the literature regarding the definition of approachability from the perception of the child in a hospital setting. Work completed thus far has set the stage but research is scarce. With such a dearth in this literature, pediatric nursing scholars, including this author are propelled to develop knowledge towards advancement of practice.

To capture the experiences of children who have been hospitalized, an inductive exploratory qualitative research study was chosen to reach out to hospitalized children through semi-structured interviews to hear their voices regarding nurses who they describe as easy to talk to. The specific research questions focused first on gaining information regarding children's perceptions of nurses who they think and feel are approachable; secondly on obtaining information about how the children describe the characteristics and behaviors of the nurses, and lastly the children's comments regarding the impact of having nurses who are approachable during their hospitalization. Seven children, ages 8 through 12 years old with a diagnosis of 
cancer and more than one hospital stay were able to identify characteristics and behaviors that reflected their perceptions of an approachable nurse. The audio-taped interviews of this convenience sample were transcribed verbatim since the intent of the researcher was to stay as close as possible to the participants' own words. In this study, qualitative content analysis was used to examine both manifest and latent data in the text from each child. Drawing was added as a non-threatening means of communication. As the children drew, their vision of what they often called "the perfect nurse" or "the approachable nurse" came to life as they were able to share great detail in relation to the appearance and specific behaviors that they identified with an approachable nurse. Data were collected over a four month period both at the outpatient pediatric oncology clinic and inpatient pediatric oncology unit at Mercy Children's Hospital in Southern New England.

The findings of this study confirm and contrast with previously documented results from the psychological research, the author's concept analysis and nursing research, adding greater depth and insight from the perceptions of these 7 children. In congruence with the psychological literature, all of the children in this study expressed the importance of the smile in relation to the nurse that is easiest to talk to. The importance of body language was not directly addressed but behaviors such as taking the time to listen and talk along with being playful when appropriate was connected with the approachable nurse. In an attempt to determine if the children in this study brought forth a sense that there was an initial judgement of approachability, certain comments surfaced. Santa Claus mentioned that nurses should not "look scary" in an attempt to describe the nurse she would approach. All of the children noted the 
importance of the smile which would propel them to approach. Two of the children in this study mentioned the importance of a nurse with scrubs and clogs with patterns and designs as one who looked "fun" and they would be likely to approach. These comments allude to the idea that children may judge approachability by appearance and facial expressions.

Similarities did exist between the results of the concept analysis and the perceptions of these children. Hobbs in particular concurred that approachable nurses are genuine and "don't smile too much" because "they should be themselves." All of the children seemed to expect that the nurses would approach them and be both verbally and nonverbally engaging. The concept analysis brought forth the idea that approachable nurses should be conscious of age appropriate language and behaviors and create a dynamic relationship. All of these children wanted dialogue and conversation to "get to know the nurse and for the nurse to get to know them." Jayson specifically mentioned the unique relationship he had with his favorite nurse and how that relationship "got him through the tough times." Each child in this study was able to quickly identify one and some up to 3 nurses who were there favorite on the unit. Within the descriptions of these favorite nurses, each child was able to allude to the unique ways in which they were able to connect. Wolverine, Vladimir and Hobbs described the receptiveness of the nurse as was seen in the concept analysis as a defining characteristic that reflected his/her approachability.

In relation to the nursing literature, researchers found as they spoke to children about the hospital experience, that nurses do have an impact on the hospital stay (Coyne \& Kirwan, 2012). The children in this study concur that the qualities of the 
nurse carried a substantial impact on the way in which the children were able to cope with hospitalization. The approachable nurse seemed to create an atmosphere of comfort, decrease fear and anxiety in the child and with reoccurring visits and ameliorate the stress of return. These characteristics were seen in the nursing literature and affirmed in the current study.

\section{Conclusions}

The findings of this study aligned closely with the research questions presented. The data collected provided detailed information regarding children's perceptions of nurses who they thought and felt were approachable. The researcher, privileged to interview these 7 children, was able to gain this information through semi-structured interviews and drawings. The children reported that approachable nurses were "smiling and happy" which created a sense of comfort and "feeling welcome and at home." Other perceptions of approachable nurses from these children included those who approached them regularly, or as one said "check in on you." These children perceived nurses who were easiest to talk to as those who took the time to talk and listen and get to know them. These behaviors seemed to engender a sense of genuine concern.

The children were easily able to describe the characteristics and behaviors of approachable nurses. All of the children described the nurses who were easiest to talk to as those who were "nice." They used the word nice and individually explained what they meant by this descriptor. It was often specific acts of kindness that correlated with nice. Two of the children mentioned that the nurses easier to approach would be wearing colorful or printed scrubs and/or clogs. Feeling safe with a nurse 
was another behavior of an approachable nurse along with the nurse who was creative in ways to ease pain or discomfort for the child. Every child recognized the importance of humor as a pivotal behavior of a nurse who was approachable. The children used the words "fun and funny" to describe the nurses who made them laugh, feel happy and forget they were even in the hospital. The children freely described the nurses who were easiest to talk to and clearly explained why.

The children were able to comment about the impact of having nurses who were approachable during their hospitalization. The impact of knowing was described by the children with vigor. Each child echoed the importance of having knowledge about what would be happening to them before a procedure and during hospitalization. Two of the children reported the importance of the nurse knowing how much information the child was ready to hear and when to stop. By knowing what to expect, the children reported less anxiety and fear of the unknown.

There was great impact surrounding the nurse who took time to talk and listen to the children. These children described the impact as feeling understood and providing distraction. The interviewed children also emphasized the positive impact of having an approachable nurse who was funny. The humor, laughter and fun with the nurses were mentioned with great joy as they remembered specific events. While home, these children recalled the fun they had with the nurses and did not feel as bad to return when necessary. The creative nurse impacted the child as he/she was able to resourcefully find ways to make the experience more tolerable. Knowing a nurse would care enough to use innovative means to care for the child, expressed implicit compassion. The impact of attire created a sense of fun and comfort for two of the 
children in this study. These 2 enjoyed scrubs and clogs that were printed and colorful. Finally, the children reported that competent nurses provided them with a sense of safety and security to lessen distress and apprehension.

In conclusion, listening to these hospitalized children and hearing the impact of the nurses' verbal and nonverbal communication, a sense of unquestionable obligation to ascertain and implement attributes that resemble approachability became evident to the researcher. The data collected provided information that answered all 3 of the research questions in great detail. In some instances, more knowledge than expected was gained.

\section{Limitations}

National statistics verify that many children will be diagnosed and treated in a specialized pediatric oncology center every year. In 2014, it was estimated that 15,780 children and adolescents ages 0 to 19 years will be diagnosed with cancer and 1,960 will die of the disease in the United States (Ward, DeSantis, Robbins, Kohler, \& Jemal, 2014). Other statistics verify the need for specialized care inpatient. In general, cancer is diagnosed each year in about 175,000 children ages 14 and under worldwide. Cancer is also the leading cause of death by disease past infancy for children in the United States. Thankfully, with advanced care, more than $80 \%$ of children in the United States will become long term survivors, depending on the type of cancer. Pediatric nurses worldwide will likely encounter a child with cancer during their career as about 420,000 childhood cancer survivors live in the United States and many more throughout the world (St. Jude Children's Research Hospital, 2017).

Within this study, limitations did exist as in all studies. The participants in this study were limited to school age children with an oncology diagnosis which limits 
generalizability outside this population. The children did not represent a diverse group as all were Caucasian with the exception of the one boy from India. If children were selected from early childhood, preschool or adolescence, one would expect their perceptions to have been different.

Children from early childhood, age 2-3 years, would have limited vocabulary and cognition, with apprehension to answer related to the ability to understand the interview questions. Simple words would need to be used during an interview and children of this age group, due to separation anxiety and negativism, may be reluctant to participate. A common response from this age group is the typical "No." Drawings may be limited to obscure presentations of mixed colors, likely with little meaning related to restricted fine and gross motor control and reasoning. Children of this age group may also be prone to putting crayons in their mouth therefore greater vigilance would be required.

Preschool children, ages 3-5 years may describe the approachable nurse with such words as "silly" instead of "fun and funny" as was used by the interviewed. These preschool children may also have limited vocabulary and comprehension skills insufficient for understanding questions and therefore, difficulty responding. Simple language would need to be incorporated in an attempt to provoke understanding but may be difficult to guarantee. Drawings for a preschool child may be slightly advanced from early childhood but questioning would need to prevail to assure interpretation.

If subjects selected were from adolescence, ages 13-18 years, they may perceive the approachable nurses not so much as playful but possibly as "cool" and 
respectful of privacy. The perception of humor may vary with adolescents as they may not find it funny to squirt nurses with needless syringes of water as these children did but rather prefer other forms of joking or laughter. Talking and recurrent episodes of dialogue may not be associated with the approachable nurse for a teen as they may prefer privacy and time alone. Adolescents may not be as willing to draw pictures as did the school age group of children related to their idea of being too old and mature for that type of activity.

Access to subjects became a limitation related to the availability of school age children, 6-12 years of age within the time frame of the study. If the researcher was not on a timeline, a full year or more may have provided a greater number of inpatient children within the school age group and not necessitated recruiting children currently being seen in a clinic rather than the hospital. The predictability of recruitment of children within this age group is variable. Due to the necessary care provided to the children during the interviews, there were often interruptions. With a quick recap of previous questions and discussion topic, however, these children were able to return to the topic of the interview.

\section{Implications}

Future research. To date, this is the first qualitative research study known to the researcher, that has explored the perceptions of school age children, related to nurses who are approachable in an inpatient setting. The children in this study have given one voice and their perceptions, supported by The United Nations' treaty, titled Convention on the Rights of the Child in 1989. More qualitative research studies with diverse groups of participants including a variety of children from different age groups 
and ethnic backgrounds need to be conducted.

Further exploration in several areas of communication with hospitalized children is needed to enhance clinical practice. This research brings out the value of hearing the voice of the school age child and the need for further work with this group and others. Possible areas to explore include approachability and tolerance of painful procedures, approachability and its impact on atraumatic care and family centered care along with the need for approachability and its meaning from the perception of the child and nurse during hospital interactions. It would be important to investigate the perceptions of approachability from the preschool, early childhood and adolescent age groups to provide greater understanding by hearing their voice. The voice of these children provide researchers and clinicians with great possibilities of areas to be investigated moving forward. Ultimately, future research and theoretical understanding will contribute to advancing clinical practice and knowledge development surrounding therapeutic communication with a focus on the approachability of the pediatric nurse.

It would be beneficial to gain more knowledge on children with other chronic diagnoses versus those with acute, short term hospital stays in particular. The impact of approachability may be greater for children over longer hospital stays whereas children sustaining short stays may not be as affected. The children interviewed carried a diagnosis of cancer wich can convey a sense of mortality; creating different perceptions based on innate fears, whereas other chronic diagnoses that are not life threatening may eliminate unsaid concerns. Those children with short term diagnoses who may be hospitalized for a one time illness or procedure that is quickly resolved 
may have perceptions of nurses that could revolve around the few nurses encountered during one hospital stay which may be positive or negative but based on a very short hospital experience.

Research should be completed with oncology patients in other children's hospitals along with those who may be inpatient on a unit that is not based in a pediatric facility but possibly a community based health care center or general care facility. The culture of nursing can differ based on units within the same children's hospital and certainly from hospital to hospital based on the personality, educational preparation and experience of nurses, priorities for care and expectations upheld by hospital administration and nurse managers for practice. Children's' hospitals focus care completely around the needs of the child whereas general health care facilities provide care across a wide spectrum of ages and diagnoses. Nurses who float or are per diem within a children's hospital, may change unit specialty but remain with a pediatric focus whereas the same nurses in a general care hospital may have a different knowledge base and communication skills if transferring from an adult or geriatric unit to a pediatric floor, therefore creating significantly different perceptions from children of the approachable nurse. Nurses who have little knowledge and experience with ill children or children in general, may not have the communication skill needed to be approachable and effectively interact.

There is also a need to expand this avenue of research to hear the voice of the pediatric nurse in relation to their perceptions of approachability. Similar qualitative work with interviews could advance knowledge and create insight into the characteristics and behaviors pediatric nurses think and feel are approachable along 
with how theses nurses feel being approachable impacts the hospitalized child. It may be beneficial to conduct research with nurses on different units within the same children's hospital and compare data amongst nurses within an alternate pediatric health care facility and then contrast with those in a general care hospital. Factors that might influence a nurse's level of approachability include education, priorities, knowledge in pediatric growth and development, and personal expectations of nursing excellence. Perceptions of nurses may differ and therefore impact communication.

Theory development. Further work is needed to develop a definition of the concept of approachability and create greater understanding around the impact of the approachability of nurses on children in an inpatient setting. Nursing practice should be integrated closely with theory. The interpretation of the concept of approachability within the theory of symbolic interactionism may be a beneficial next step for linking the concept with an existing theory.

Once the definition of the concept is further refined, one would want to consider the possibility of developing a tool to measure the approachability of a pediatric hospital nurse or for that matter, any pediatric health care provider. A clear definition would allow the possibility of developing a scale or guide to measure a nurse's level of approachability. Implementation of knowledge and competency in practice is possible with greater awareness.

This research started with knowledge from the psychological literature on the judgement of approachability, insight from the nursing literature on the hospital experience of the child and a working definition from a Wilsonian concept analysis. Within this study, the perceptions of children gleaned knowledge towards the 
refinement of this concept. Responses from these interviews affirmed the smile as noted from the psychological literature as indicative of an approachable nurse. Time spent sharing stories, listening and talking as described by children in recollection of a positive hospital experience from previous nursing literature was reinforced by the children interviewed in this study (Coyne, 2006a; Pelander et al., 2007). Additionally, these children found the approachable nurse to smile and be playful and was seen in nursing literature, again reinforcing these attributes as a possible base for identifying the presence of an approachable nurse (Pelander et al. 2007; Pena \& Juan, 2011). Repetition of similar characteristics and behaviors will help to further define and measure the concept of approachability and its use under the umbrella of the theory of symbolic interactionism which may help to further explain its impact in practice.

Symbolic interactionism is a theory that could possibly guide future research related to understanding human interaction and meaning related to the approachable nurse and the pediatric oncology patient. One of the significant and important tenets of this theory is that the person and the environment are in constant interaction. One cannot exist without the other. "Truth is tentative and never absolute because meaning changes depending on the context of the individual" (Benzies \& Allen, 2001, p. 544). Individuals must be heard to define and interpret meaning via the reality of the social context.

Within the symbolic interactionist perspective, nursing research occurs within the natural world of the client. This perspective could enable the researcher to describe and understand the perception of the child regarding the concept of approachability within the interaction with the pediatric nurse in an inpatient setting. 
The voice of the child, in future research, could be heard to derive meaning from symbols displayed.

Education. A number of areas have been identified in this study that are related to the facilitation of improved nurse-patient communication and the hospital experience. The results can be used as a point of discussion in educational offerings both in undergraduate nursing degree curriculum and as part of required certified educational training programs if not currently present for practicing nurses and those in the academic arena. Currently, the term "therapeutic communication" is mentioned within the curriculum of beginning level nursing textbooks (Halter, M.J., 2014; Taylor et al., 2015). A great deal of content emphasizes the need for knowledge related to growth and development in pediatrics but to the knowledge of the researcher, content does not exist that emphasizes the behaviors or characteristics that make a pediatric nurse approachable to a hospitalized child. With increased awareness regarding the benefits of the approachable nurse, further education and training would be beneficial within every aspect of pediatric education, orientation and renewed certification. Knowledge regarding the impact of the approachable nurse during and after the hospitalization of children may reinforce the value of these behaviors and characteristics.

Education regarding approachability in pediatric nursing could be incorporated through simulation and the clinical experience. The results of this study can be used to address the weakness in curricula both in the academic setting and within the workplace, provoking educators to expand current content. Communication skills should be considered a priority of course curriculum in undergraduate nursing 
programs and job training and evaluation. Inviting children to speak and share experiences during training sessions may also be incorporated to accentuate the voice of the child and raise awareness of the potential importance of approachable nurses. Textbook knowledge would create a rationale that may be most appropriately learned through active engagement with children in hospital and through active simulation and debriefing, preferably with live children as opposed to manikins. There is also a need to think about ways to create an awareness of the need for pediatric nurses to be approachable. Providing clinical education for pediatric nurses and students regarding the behaviors and characteristics of an approachable nurse could be a stepping stone toward the actualization of the 1989 United Nations Treaty on the Rights of the Child, while enhancing the interaction between the nurse and the hospitalized child.

Nursing administration. The goal of nursing administration is to organize and assure quality healthcare wherein the attention provided by nurses to children is based on knowledge, skills and attitudes. The profession of nursing is based on standards, specifically those established for pediatrics and supported by the American Nurses Association. Within the definition of a Generalist Pediatric Nurse, the American Nurses Association states, in relation to competencies, that the nurse should be able to "effectively communicate with children and families" (ANA, 2008, p. 17). Updated standards revised in 2015 by the ANA identify communication as the eleventh essential standard of practice for the pediatric nurse wherein he/she, as a registered nurse, is required to "communicate effectively in a variety of formats in all areas of practice" (ANA, 2015, p.70). Nursing leaders might consider implementing approachability as a point of discussion to support a culture of caring and respect. 
Nurse Managers could think about incorporating knowledge and training into the orientation of new nurses and creating a peer review wherein nurses are held accountable for both verbal and nonverbal communication skills if one does not currently exist. To enhance practice excellence, nurse leaders could include necessary criteria within peer review or evaluations related to communication to raise awareness of the need for pediatric nurses to gain skills in behaviors of approachability. It should be the responsibility of administration to consider this competence in maintaining a high standard of care.

Clinical practice. There are a number of implications that can be considered in clinical practice when communicating with a child in the hospital. Staff nurses engage with children frequently throughout the inpatient stay. Nurses are the only providers that remain with the children throughout hospitalization and it therefore should be the expectation that nurses will advocate and meet all needs. According to the many theories of growth and development, children go through stages. Language and cognition develop as children mature and it is generally expected that a priority of pediatric nurses is to be knowledgeable and sensitive to the developmental stage of the child, understanding fears and concerns (Hockenberry \& Wilson, 2011).

A vulnerable population, hospitalized children are at risk for marginalization (UNCRC, 1989b). Pediatric nurses should be comfortable with communication skills that are age appropriate and be approachable to all children. It may be beneficial if training was required for all nurses to uphold an expectation of behavior and dialogue while caring for children in the hospital. Pediatric nurses should be cognizant of their verbal and nonverbal communication while in practice. Nurses may need to be aware 
of the impact of their actions and presence on the children both inpatient and

following hospitalization. It is recommended that the responsibility remains with nurses to create a safe environment wherein hospitalized children feel comfortable and know their voices are heard, they are understood and respected with unprecedented dignity (Coyne \& Kirwan, 2012). 


\section{Appendix A: Lifespan IRB expedited review/approval letter}

\begin{tabular}{|c|c|c|}
\hline$\frac{3}{2} \geqq$ Life & & \\
\hline \multicolumn{2}{|c|}{$\begin{array}{l}\text { Research Protection Office } \\
\text { Office of Research Administration } \\
\text { CORO West, Suite } 1.300 \\
\text { One Hoppin Street } \\
\text { Providence, RI 02903 } \\
\text { Tel } 401 \text { 444-6246, Fax } 401444-7960\end{array}$} & $\begin{array}{l}\text { E. P. Bradley Hospital } \\
\text { Rhode Island Hospital } \\
\text { The Miriam Hospital } \\
\text { Newport Hospital } \\
\text { Gateway Healthcare }\end{array}$ \\
\hline DATE: & \multicolumn{2}{|c|}{ March 2, 2017} \\
\hline TO: & \multicolumn{2}{|c|}{ Francine Pingitore, $\mathrm{PhD}$} \\
\hline FROM: & \multicolumn{2}{|c|}{$\begin{array}{l}\text { Janice Muratori, MSN, FNP-BC } \\
\text { Director, Research Protection Office }\end{array}$} \\
\hline SUBJECT: & \multicolumn{2}{|c|}{$\begin{array}{l}\text { REVISION IRB APPROVAL LETTER } \\
\text { FWA-Rhode Island Hospital (RIH) 00001230, The Miriam Hospital (TMH) } \\
\text { 00003538 } \\
\text { IRB Registration \#s: RIH IRB } 1 \text { - } 00000396 \text {, RIH IRB } 2 \text { - } 00004624 \text {, TMH IRB } \\
\text { - } 00000482\end{array}$} \\
\hline CMTT/PROJ: & \multicolumn{2}{|c|}{01941645 CFR46.110 (5)(6)(7) } \\
\hline TITLE: & \multicolumn{2}{|c|}{$\begin{array}{l}\text { [943703-6,7] A Description of Approachable Nurses: The Voice of the } \\
\text { Hospitalized Child }\end{array}$} \\
\hline DECISION DATE: & \multicolumn{2}{|c|}{ February 20, 2017} \\
\hline
\end{tabular}

Thank you for submitting the Revision materials for this project. The Lifespan - Rhode Island Hospital IRB 1 has approved your submission on February 20,2017. Requested IRB revisions were received and accepted February 28, 2017. No further action on submission $943703-6,7$ is required at this time.

The following items are approved in this submission:

- Amendment/Modification - RTP add tomorrow fund to protocol, consent, flyer IRB edits 2-16-17.pdf (UPDATED: 02/16/2017)

- Consent Form - ICF_Child highlighted Coia 2-17.doc (UPDATED: 02/10/2017)

- Consent Form - ICF_Child clean copy Coia 2-17.doc (UPDATED: 02/10/2017)

- Letter - Letter of Cooperation AR, Tomorrow Fund Clinic 2-17.docx (UPDATED: 02/13/2017)

- Other - Recruitment flyer.highlighted 2.9.17.docx (UPDATED: 02/10/2017)

- Other - Recruitment flyer. clean copy 2.9.17.docx (UPDATED: 02/10/2017)

- Proposal - Proposal highlighted Coia 2-17.docx (UPDATED: 02/10/2017)

- Proposal - Proposal clean copy Coia 2-17.docx (UPDATED: 02/10/2017)

- Child Assent - ChildAssent.lifespan.bcoia. clean copy.2.28.17b.docx (UPDATED: 02/28/2017)

- Child Assent - ChildAssent.lifespan.bcoia.highlightedchanges.2.28.17.docx (UPDATED: 02/28/2017)

If you have any questions, please contact Elizabeth Pisaturo at (401) 444-7547 or elizabeth.pisaturo@lifespan.org. 
REMINDER: RESEARCH DATA SHOULD ONLY BE STORED ON LIFESPAN MANAGED DEVICES AND AUTHORIZED ENCRYPTED THUMB DRIVES. In no circumstances should this data be stored on personally owned and managed devices. Obtaining consent and research authorization does not remove the requirements and restrictions of the HIPAA Security Rule. For more information contact Janice Muratori at (401)444-6897, JMuratori@lifespan.org.

This document has been electronically signed in accordance with all applicable regulations, and a copy is retained within our records. 
Research Protection Office

Office of Research Administration

CORO West, Suite 1.300

One Hoppin Street

Providence, RI 02903

Tel 401 444-6246, Fax 401 444-7960
E. P. Bradley Hospital Rhode Island Hospital The Miriam Hospita

Newport Hospital

Gateway Healthcare
DATE:

TO:

FROM:

SUBJECT:

CMTT/PROJ:

TITLE:
December 8, 2016

Francine Pingitore, $\mathrm{PhD}$

Janice Muratori, MSN, FNP-BC

Director, Research Protection Office

HUMAN SUBJECTS PROTECTION of NeW Project AS PER EXPEDITED

\section{REVIEW}

FWA-Rhode Island Hospital (RIH) 00001230, The Miriam Hospital (TMH) 00003538

IRB Registration \#s: RIH IRB 1 - 00000396, RIH IRB 2 - 00004624, TMH IRB $-00000482$

019416 45CFR46.110(5)(6)(7)

[943703-1, 3, 4 and 5] A Description of Approachable Nurses: the voice of the hospitalized child

Your research project was reviewed and approved on October 31, 2016. Requested IRB revisions were received and accepted on December 7, 2016. This research has been approved as meeting the expedited criteria for the protection of humans per 45 CFR 46.110(5)(6)(7) by the Lifespan - Rhode Island Hospital IRB 1. This institution is in compliance with the ICH GCP as they correspond to the FDA/DHHS regulations. This review and approval are applicable for RIH.

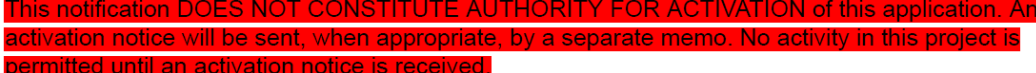

Your protocol involves children and has been reviewed according to subpart $D$ of the regulations and classified as Category A according to Federal pediatric assent guidelines. Please follow the instructions indicated for this classification.

It is the responsibility of the principal investigator to ensure that the study is conducted as approved by the IRB. All protocol modifications/changes must be approved by the IRB before any changes are implemented except when necessary to eliminate immediate hazards to subjects.

If written informed consent is required for this study: The newly stamped consents are included with this letter. Please review these informed consents to be sure you have received all the documents necessary to conduct this study. Please be sure all informed consents you submitted for approval, specimen banking forms and ads if applicable, are included and stamped with the approval and expiration dates. These newly stamped informed consents and other documents are to be used immediately for this study and supersede any previously issued documents, if applicable. 
You are required by Federal regulations and Hospital policy to immediately report any unanticipated problems, untoward effects or reactions, serious side effects and/or deaths of subjects involved and related to this project to the IRB through the Research Protection Office.

IRB approval for this project expires on October 30, 2017. If you wish to continue your research after this date you are required to submit a continuation report (CR) prior to expiration of approval. A reminder notice will be sent approximately 30 days before the continuation report is due. The CR must be reviewed by the IRB no later than the date of expiration in order for the study to be in compliance with federal regulations. Federal regulations do not allow for ANY grace period for renewal.

Please provide a termination report to the IRB when the research is completed and IRB approval may be terminated.

REMINDER: RESEARCH DATA SHOULD ONLY BE STORED ON LIFESPAN MANAGED DEVICES AND AUTHORIZED ENCRYPTED THUMB DRIVES. In no circumstances should this data be stored on personally owned and managed devices. Obtaining consent and research authorization does not remove the requirements and restrictions of the HIPAA Security Rule. For more information contact Janice Muratori at (401)444-6897, JMuratori@lifespan.org.

This document has been electronically signed in accordance with all applicable regulations, and a copy is retained within our records. 


\section{Appendix B: IAA agreement between Lifespan and URI}

IRB Authorization Agreement

Name of Institution or Organization Providing IRB Review: Rhode Island Hospital

IRB Registration \#:0000396

Federalwide Assurance (FWA) \# FWA00001230

Name of Institution Relying on the Designated IRB: University of Rhode Island

IRB Registration \#:00000599

Federalwide Assurance (FWA) \#, 00003-132

The Officials signing below agree that University of Rhode Island may rely on the designated.IRB of Rhode Island Hospital IRB \#1 for review and continuing oversight of its specific human subject research protocol, described below:

Study Title: A Description Of Approachable Nurses: the voice of the hospitalized child Name of RIH. Principal Investigator: Francine R.B. Pingitore PhD

RIH \#1 IRB Committee 019416

Study Title: A Description of Approachable Nurses: the roice of the hospitalized child University of Rhode Island Principal Investigator: Bethany Coia PhDc

(Name of other institution) File \#

The review and continuing oversight performed by the Rhode Island Hospital IRB \#l will meet the human subject's protection requirements of the University of Rhode Island OHRP-approved FWA. Rhode Island Hospital IRB \#1 will provide copies of all IRB approvals for the above project (including modifications, progress reports, and adverse event reports), to the University of Rhode Island IRB, on a timely basis, for the duration of the project.

Relevant minutes of IRB meetings will be made available to University of Rhode Island upon written request. University of Rhodes Island remains responsible for ensuring compliance with the Rhode Island Hospital IRB \#1 IRB's determinations and with the terms of its OHRP-approved Assurance. This document must be kept on file at both institutions and provided to OHRP upon request.

Signature of Signatory Official for University of Rhode Island:

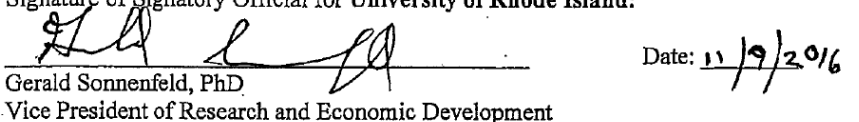

Vice President of Research and Economic Development

Signature of Signatory Official for Rhode Island Hospital:

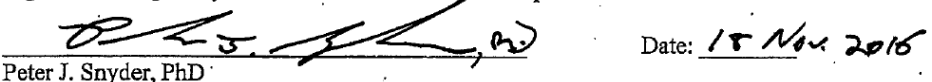

Senior Vice President and Chief Research Officer, Lifespan (RIH\#2) 


\section{Appendix C: Lifespan approved recruitment flyer}

WHAT DO YOU HAVE TO SAY?

WE WANT TO HEAR YOUR VOICE

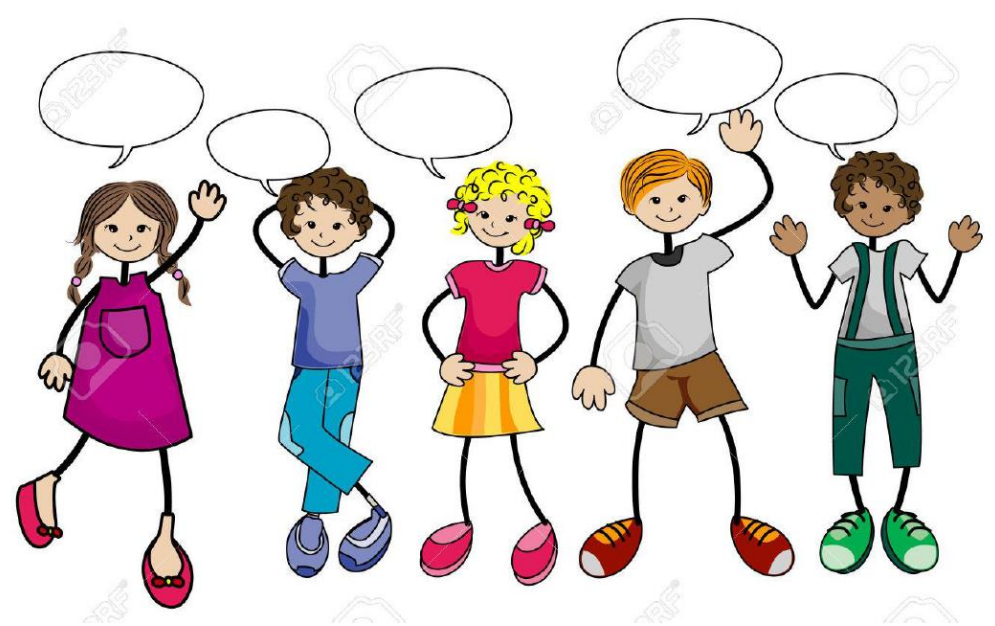

Children (6 to 12 years old) who are currently oncology patients on the $5^{\text {th }}$ floor of Hasbro Children's

Hospital and/or in the Tomorrow Clinic are invited to participate in a Lifespan research study to share their thoughts about what it means to be able to easily communicate with nurses. We are interested in learning from you so that we can assure that your voice and the voices of all hospitalized children are always heard.

If you are interested, please contact:

Francine Pingitore RN, PhD 401-444-5636

fpingitore@lifespan.org

Bethany Coia RN, PhDc 632-7643

bcoia@ric.edu 


\section{Appendix D: Lifespan approved Consent to Contact}

\begin{tabular}{|lr|}
\hline IRB Approval: & $10 / 31 / 2016$ \\
\hline IRB Accepted: & $12 / 7 / 2016$ \\
\hline IRB Expiration: & $10 / 30 / 2017$ \\
\hline
\end{tabular}

A Description of Approachable Nurses: the voice of the hospitalized child

There is an opportunity for you to allow your child to participate in a research study that focuses on your child's perceptions of his/her nursing care while he/she is an in-patient at Hasbro Children's hospital. If you would like to hear more about the study, please sign your name below. A member of the Research Staff will contact you to tell you more and answer your questions. You and your child are never obligated to sign up for a study, and you may ask us to take you off of our contact list at any time.

YES, a Research Staff member may contact me to tell me more about the approachable nurses study.

YES, a Research Staff member may leave a message.

Signature of Parent / Guardian

Printed name of parent / guardian:

Printed name of child:

Child's birth date:

Child's diagnosis or reason for office visit:

Home phone number:

Cell phone number:

Work phone number:

Address (Street, apartment number):

Address (City, State \& Zip): 


\title{
Appendix E: Lifespan approved Parental Consent
}

Lifespan Affiliate Site where research will be conducted
\[ \begin{array}{ll}\square \text { Rhode Island Hospital } & \square \text { The Miriam Hospital } \\ \square \text { Bradley Hospital } & \square \text { Newport Hospital } \\ & \square \text { Gateway Healtheare }\end{array} \]

\section{Agreement to Participate in a Research Study And Authorization for Use and Disclosure of Information}

\author{
$\frac{0194-16}{\text { Committee \# }}$
}

\author{
Name of Study volunteer
}

A Description of Approachable Nurses: the voice of the hospitalized child

Your child is being asked to take part in a research study. All research studies at Lifespan hospitals follow the rules of the state of Rhode Island, the United States government and Lifespan. Before you decide whether to allow your child to be in the study, you and the researcher will engage in the "informed consent" process. During this process, the researcher will explain the purpose of the study, how it will be carried out, and what your child will be expected to do if they participate. The researcher will also explain the possible risks and benefits of being in the study, and will provide other information. You should feel free to ask any questions you might have. The purpose of these discussions is for you to decide whether participating in the study is the best decision for your child.

If you decide to allow your child to be in the study, you will be asked to sign an agreement which states that the study has been explained, that your questions have been answered, and that you agree to have your child participate. You will be given a copy of this form to keep.

Federal and Lifespan institution rules require that if your child is 8 years or older, the "assent" (agreement) of your child be obtained by the researcher before your child may participate in this study. Your child must sign the consent form as well. You will be given a copy of the signed consent form to keep.

1. Nature and Purpose of the Study

Your child is being asked to take part in a research project because he/she is a pediatric oncology patient on Hasbro $5 \mathrm{and} /$ or in the Tomorrow Clinic and has been a patient on this unit previously at least once before this current stay. Therapeutic communication is critical to maintain the respect and dignity of the hospitalized child. The purpose of this study is to describe the perceptions of school age children (age 7-12 years) in relation to an approachable nurse. The researcher hopes to hear the voice of the child to gain insight and improve communication between nurses and children in an inpatient setting.

We expect to enroll 12-15 subjects into this study.

The sponsor of this study is The University of Rhode Island

RPO Minor IC and Auth - v.8-2013[3] 


\section{Explanation of Procedures}

Parents will be given a copy of the interview upon request. A member of the research staff will administer the interview. Your child will be interviewed about their perceptions of an approachable nurse (how easy it is for them to talk to their nurse). The interview will last for about 45 minutes to an hour. The questions will seek to explore what your child perceives and describes as an approachable nurse and the impact that good communication has on the hospital experience during and after previous hospitalizations.

*The interview will take place in your child's hospital room or a private conference room on the fifth floor of Hasbro Children's Hospital or in the Tomorrow Clinic.

*The interview will be audiotaped. Your child will be asked to use another name while being audiotaped to maintain confidentiality. The tapes will be kept in a locked file cabinet in a locked office. The tapes will be destroyed immediately after all study data has been analyzed.

*A \$20 gift card will be offered to your child as a thank you for taking the time to complete the interview.

Contact Information:

Francine Pingitore, $\mathrm{RN}, \mathrm{PhD}$

Hasbro Children's Hospital

593 Eddy Street

Providence, RI 02903

401-444-5636

Bethany Coia, MS, RN, PhDc

Hasbro Children's Hospital

593 Eddy Stree

Providence, RI 02903

401-632-7643

\section{Discomforts and Risks}

It is possible, though unlikely, that your child may experience emotional discomfort at some point during the interview in thinking about a question. If this happens, the researcher will check with your child regarding how he/she is feeling. Also, the researcher will ask your child if he/she is comfortable continuing the interview or if he/she would prefer to stop the interview. There is a risk that there may be a breech in confidentiality, however, the documents will be de-identified and kept in a locked cabinet, in a locked room.

\section{Benefits}

By participating in this research study and answering questions about perceptions of the approachability of the nurse, your child may gain a sense of empowerment in knowing that he/she has a voice and is able to express concealed feelings about communication with nurses during hospitalization which would be beneficial toward the child's self-esteem, and sense of personal dignity

RPO Minor IC and Auth - v.8-2013[3] 
and respect. In addition, knowledge gained from this study could be beneficial in improving the nursechild relationship for school age children in the future.

5. Alternative Therapies

Your child does not have to participate in this research study.

6. Refusal/Withdrawal

It is up to you whether you want your child to be in the study. You are not required to enroll your child or participate. If you decide you want your child to participate, you can always

change your mind and remove them from the study at any time. If you decide not to have your child be in the study, or if you remove them later, your child will still be able to get the health care services they would normally get. If you enroll your child but later on the researcher or your doctor feels being in the study is no longer good for your child, they may choose to take your child out of the study before it is over. If new information becomes available that might change your mind about whether you want your child to stay in the study the researcher will share this information with you as soon as possible.

\section{Medical Treatment/Payment in Case of Injury}

a. A research injury is any physical or mental injury or illness caused by being in the study. If your child is injured by a medical treatment or procedure they would have received even if they were not in the study that is not a research injury. To help avoid research injury and added medical expenses, it is very important to follow all study directions carefully. If your child does experience a research injury, Lifespan or the study doctor can arrange medical treatment for them. Such treatment will be paid for as described below.

The sponsor of this study does not cover any research related injuries.

If you have insurance and your child has a research injury that is not covered by the study, it is possible that some or all of the cost of treating your child could be billed to your insurer. If your health insurance will not cover such costs, it is possible you would have to pay out of pocket. In some cases, Lifespan might be able to help you pay if you qualify for free care under Lifespan policy. However, Lifespan has no policy to cover payment for such things as lost wages, expenses other than medical care, or pain and suffering.

\section{$\underline{\text { Rights and Complaints }}$}

Signing this form does not take away any of your lawful rights. If you or your child have any complaints about your child's participation in this study, or would like more facts about the rules for research studies, or the rights of people who take part in those studies, you may contact Janice Muratori, anonymously if you wish, in the Lifespan Office of Research Administration, telephone number (401) 444-6246

$\underline{8}$ Confidentiality and Research Authorization for Use and Disclosure of Your Health Care Information.

RPO Minor IC and Auth - v.8-2013[3] 
Parent/Guardian Initials

Your child's research records will be treated as private health care records and will be protected according to Lifespan privacy practices and policies that are based on state and federal law. In particular, federal law requires us to get your permission to use or disclose (release your child's information to someone outside of Lifespan) their health information for research purposes. If you sign this form you agree to have your child be in this research study and you permit the use and disclosure of your child's health information for the purpose of conducting the research, providing treatment, collecting payment and running the business of the hospital. This permission has no expiration date. You may withdraw from the study at any time. However, if you do not want the researchers to use or disclose any further information in this study you must cancel permission in writing and may do so at any time. If you cancel your permission, you will stop taking part in the study and no new information will be collected about you. However, if you cancel your permission, it will not apply to actions already taken or information already collected about you by the hospital or the researchers before you canceled your permission.

Generally, the entire research record and any medical records held by the hospital may be used and released for research purposes. The following people or businesses/companies/ might use, release, or receive such information:

- The researcher and their support staff;

- Doctors, nurses, laboratories and others who provide services to you or the sponsor in connection with this study;

- The company or section of the U.S. government that is paying for the study and others they hire to oversee, administer, or conduct the research;

- The United States Food and Drug Administration, the Department of Health and Human Services, the Office of Inspector General, and the Office of Civil Rights; European Medicines Agency

- People who volunteer to be patient advocates or research volunteer protectors;

- Members of the hospital's administrative staff responsible for reviewing, approving and administering clinical trials and other healthcare or research activities.

- Accrediting Organizations

There are times when the law might require or permit Lifespan to release your child's health information without your permission. For example, Rhode Island law requires researchers and health care workers to report abuse or neglect of children to the Department of Children, Youth and Families (DCYF) and to report abuse or neglect of people age 60 and older to the Department of Elderly Affairs.

All researchers and health care providers are required to protect the privacy of your child's health care information. Other people and businesses/organizations that are not health care providers are not required by law to do that so it is possible they might re-release your child's information.

You have the right to refuse to sign this form and not allow your child to participate in the research. Your refusal would have no affect on your child's treatment, charges billed to you, or

RPO Minor IC and Auth - v.8-2013[3] 
Parent/Guardian Initials

benefits at any Lifespan health care site. If you do not sign, your child will not be able to enroll in the research study and will not receive treatment as a study participant.

If you decide to have your child quit the study after signing this form (as described in Section 6) no new information will be collected about them unless you gave us permission to do so. However, the hospital or the researchers may continue to use information that was collected before you removed your child from the study to complete analysis and reports of this research.

For more detail about privacy rights see the Lifespan Joint Privacy Notice which has or will be given to you.

SIGNATURE

I HAVE READ THE ABOVE DESCRIPTION OF THIS STUDY. ALL OF MY QUESTIONS HAVE BEEN SATISFACTORILY ANSWERED, AND, AND I GIVE PERMISSION FOR MY CHILD TO PARTICIPATE IN THIS RESEARCH STUDY.

This informed consent document expires on 10/30/2017

DO NOT sign this document after this expiration date

The Researcher is required to provide a copy of this consent to you.

\begin{tabular}{ll}
$\overline{\text { Signature of parent/guardian* }}$ & $\overline{\text { Date }}$ and $\overline{\text { Time when signed }}$ \\
\hline Signature of parent/guardian* & $\overline{\text { Date }}$ and $\overline{\text { Time when signed }}$
\end{tabular}

I AGREE TO PARTICIPATE IN THIS STUDY

Signature of study volunteer (child)*

Date

$\overline{\text { Age of study volunteer (child) }}$

RPO Minor IC and Auth - v.8-2013[3] 
I WAS PRESENT DURING THE CONSENT PROCESS AND SIGNING OF THIS AGREEMENT ABOVE BY THE PARENT/GUARDIAN OR AUTHORIZED REPRESENTATIVE

Signature of witness (required if consent

Date presented orally or at the request of the IRB)

Signature of Translator

Date

IF STUDY VOLUNTEER IS UNABLE TO SIGN OR EXCEPTION TO ASSENT IS SOUGHT, PLEASE EXPLAIN:

I CERTIFY THAT I HAVE EXPLAINED FULLY TO THE ABOVE PARENTS AND STUDY VOLUNTEER, THE NATURE AND PURPOSE, PROCEDURES AND THE POSSIBLE RISK AND POTENTIAL BENEFITS OF THIS RESEARCH STUDY.

Signature of researcher or designate $\overline{\text { Date }}$ and $\overline{\text { Time when signed }}$

* If signed by agent other than parent and study volunteer, please explain below. 


\section{Appendix F: Lifespan approved Child Assent}

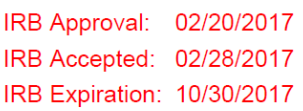

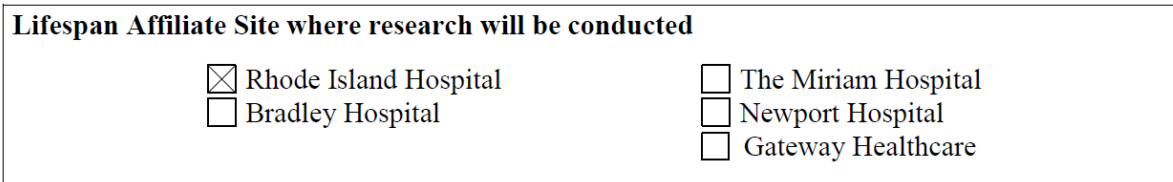

\section{Child Assent to Participate in a Research Project}

\section{STUDY TITLE}

A Description of Approachable Nurses: the voice of the hospitalized child This assent form may contain words that you do not understand. Please ask the study doctor or the study staff to explain any words or information that you do not clearly understand. You may take a copy of this assent form to think about or discuss with family or friends before making your decision

Reason for Study

We are trying to learn from children how they feel nurses can be approachable and easy to talk to so that your experience in the hospital is as pleasant as possible and you feel comfortable. We believe if we can listen to your ideas on nurses who are easy to talk to, then we can help other nurses talk in a way that hospitalized kids feel more comfortable in the future. We want to help make being in the hospital a time where you feel that you can talk to all of the nurses easily and know that you have a say in what happens to you.

\section{What kinds of things will you do if you take part in this study?}

Someone who is not your nurse will talk to you during this hospital stay or while you are in the Tomorrow Clinic. This conversation will happen in your room or in a private conference room. You will be provided with the questions that will be asked. Your parents can stay in the room if you want them to.

You will be asked some questions about nurses and what they do to make you feel like you can talk to them and tell them any of your questions or concerns. We know you have been in the hospital before so we think you can help us learn best what makes a nurse easy to talk to. The conversation will take about 45 minutes to one hour. We will tape record our talk with you to be sure we have covered all the information correctly.

How long is this study?

The length of the study is a one-time conversation that will last about 45 minutes to one hour.

Will you feel uncomfortable during the study?

$08 / 13$

Approachable Nurses
Page 1 of 2

Study Version Date 9/13/16 
We do not expect any problems, although you may sometimes feel uncomfortable answering some of the questions. If you feel uncomfortable, the researcher will talk with you and be sure you feel OK to finish the conversation. You will receive a gift certificate for $\$ 20$ after you finish talking with the researcher.

\section{Contact Information:}

Francine Pingitore, $\mathrm{RN}, \mathrm{PhD}$

Hasbro Children's Hospital

593 Eddy Street

Providence, RI 02903

401-444-5636

Bethany Coia, RN, PhDc

Hasbro Children's Hospital

593 Eddy Street

Providence, RI 02903

401-632-7643

\section{Refusal/Withdrawal}

It is up to you whether you want to be in the study. If you decide to be in the study now, you can always change your mind and quit at any time. If you decide not to be in the study, or if you quit later, you will still be able to get treated.

\section{Complaints or Questions about Research}

If you have any problems with this study, or would like know more about you may contact

Janice Muratori in the Lifespan Office of Research Administration, at (401) 444-6246

Your mom, dad, and/or guardian know about this study, and they think it is OK for you to be in this study. If you want to be in this study, you can tell the researcher and sign your parents' form. If you do not want to be in the study, it is OK to say no. You can stop being in the study any time you want to, and nobody will be upset with you.

$08 / 13$ 


\section{Appendix G: Lifespan approved Interview Guide}

\begin{tabular}{|lr|}
\hline IRB Approval: & $10 / 31 / 2016$ \\
\hline IRB Accepted: & $12 / 7 / 2016$ \\
\hline IRB Expiration: & $10 / 30 / 2017$ \\
\hline & \\
Interview Guide
\end{tabular}

1. Tell me about the nurses on this unit.

Probes:

a. When you think of the nurses here that are the easiest to talk to, what are they like?

b. When you know you are coming to the hospital and will be admitted for treatment, what comes to your mind when you think about the nurses? 
2. If you could choose any nurse on this unit to take care of you, who would it be? Why?

\section{Probes:}

a. Why do you think it is easier to talk to him/her than any other nurse?

b. When you first saw this nurse, what did you think?

c. What does this nurse do to make you smile and feel comfortable in the hospital? 
3. Draw me a picture of what you think the perfect nurse should look like and tell me how he/she should act with kids in the hospital? 
4. What do you wish a nurse could know about how a child feels in the hospital?

Probes:

a. If you had the chance to talk to a bunch of nurses who take care of children in the hospital, what would you tell them?

b. How should nurses act, behave and talk to kids?

c. While you are in the hospital, what can the nurses do to make your stay easier and less scary? 
5. When you go home or back to school, do you think about your hospital stay? What things come to your mind?

Probes:

a. What do you remember most when you leave the hospital?

b. If your mom or dad tells you that you have to go back to the hospital, what is the first thing that comes to your mind? 


\section{Bibliography}

American Nurses Association. (2008). Pediatric nursing: Scope and standards of practice $\left(1^{\text {st }}\right.$ ed.). Silver Spring, MD.

American Nurses Association (2015). Pediatric nursing: Scope and standards of practice ( $2^{\text {nd }}$ ed.). Silver Spring, MD.

Benzies K. M., \& Allen, M. N. (2001). Symbolic interactionism as a theoretical perspective for multiple method research. Journal of Advanced Nursing, 33, 541-547. doi:2048/10.1046/j.1365-2648.2001.01680.x

Berelson, B. (1952). Content analysis in communication research. Glencoe, IL: The Free Press.

Bernard, H. \& Ryan, G. (2010). Analyzing qualitative data: Systematic approaches ( $1^{\text {st }}$ ed.). Los Angeles, CA: SAGE Publications.

Bricher, G. (1999). Paediatric nurses, children and the development of trust. Journal of Clinical Nursing, 8, 451-458.

Brady, M. (2009). Hospitalized children's views of the good nurse. Nursing Ethics, $16(5), 543-560$.

Campbell, D., Neuert, T., Friesen, K., \& McKeen, N. (2010). Assessing social approachability: Individual differences, in-group biases, and experimental control. Canadian Journal of Behavioral Science, 42(4), 254-263.doi: $10.1037 / \mathrm{a} 0020229$

Campbell, S., O’Malley, C., Watson, D., Charlwood, J., \& Lowson, S. (2000). The image of the children's nurse: A study of the qualities required by families of children's nurses' uniform. Journal of Clinical Nursing, 9, 71-82.

Cotton, B. \& Schwartz-Barcott, D. (2016). Residential instability among low-income families: A concept analysis. Archives of Psychiatric Nursing Journal, 30(2), 257-261. Doi: 10.1016/j.apnu.2015.11.006

Coyne, I. (2006a). Children's experiences of hospitalization. Journal of Child Health Care, 10(4). 326-336. doi: 10.1177/1367493506067884.

Coyne I. (2006b). Consultation with children in hospital: Children, parents' and nurses' perspectives. Journal of Clinical Nursing, 15(1):61-71. PMID: 16390525

Coyne, I. (2008). Children's participation in consultations and decision-making at health service level: A review of the literature. International Journal of Nursing Studies, 45(11), 1682-1689. 
Coyne, I., Amory, A., Kiernan, G., \& Gibson, F. (2014). Children's participation in shared decision-making: Children, adolescents, parents and healthcare professionals' perspectives and experiences. European Journal of Oncology Nursing, 18(3), 273-280. doi:10.1016/j.ejon.2014.01.006

Coyne, I., \& Gallagher, P. (2011). Participation in communication and decisionmaking: Children and young people's experiences in a hospital setting. Journal of Clinical Nursing, 20, 2334-2343. doi: 10.1111/j.13652702.2010.03582.x

Coyne, I., Hayes, E., Gallagher, P., \& Regan, G. (2006). Giving children a voice: Investigation of children's experiences of participation in consultation and decision-making in Irish hospitals. Dublin: Office of the Minister for Children.

Coyne, I., \& Kirwan, L. (2012). Ascertaining children's wishes and feelings about hospital life. Journal of Child Health Care, 16(3), 293-304. doi: $10.1177 / 1367493512443905$

Denzin, N. K., \& Lincoln, Y. S. (1994). Introduction: Entering the field of qualitative research. In N. K. Denzin \& Y.S. Lincoln (Eds.), Handbook of qualitative research (pp. 1-17). Thousand Oaks: Sage Publications.

Downe-Wamboldt, B. (1992). Content analysis: Method, applications \& issues. Health Care Women International, 13(3), 313-321. doi: 10.1080/07399339209516006

Fontana, A. \& Frey, J. H. (2000). The interview: From structured questions to negotiated text. In N. K. Denzin \& Y.S. Lincoln (Eds.), Handbook of qualitative research (pp. 645-672). Thousand Oaks: Sage Publications.

Graneheim, U., \& Lundman, B. (2004). Qualitative content analysis in nursing research: Concepts, procedures and measures to achieve trustworthiness. Nursing Education Today, 24, 105-112.

Halter, M. J. (2014). Foundations of psychiatric mental health nursing: A clinical approach $\left(7^{\text {th }}\right.$ ed.). St. Louis, MO: Saunders Elsevier.

Hockenberry, M. J. \& Wilson, D. (2011). Wong's nursing care of infants and children ( $9^{\text {th }}$ ed.). St. Louis, MO: Mosby.

Hsieh, H. F., \& Shannon, S. E. (2005). Three approaches to qualitative content analysis. Qualitative Health Research, 15(9), 1277-1288. doi:10.1177/1049732305276687

Kim, H. S. (2015). The essence of nursing practice: Philosophy and perspective $\left(1^{\text {st }}\right.$ ed.) New York: Springer Publishing Co. 
Kondracki, N. L. (2002). Content analysis: Review of methods and their applications in nutrition education. Journal of Nutrition Education Behavior, 34(4), 224230.

Kracauer, S. (1952). The challenge of qualitative content analysis. Public Opinion Quarterly, 16(4), 631-642. doi: 10.1086/266427

Krippendorff, K. (2013). Content analysis: An introduction to its methodology (3rd ed.). Los Angeles: SAGE.

Lambert, V., Glacken, M., \& McCarron, M. (2008). 'Visible-ness': The nature of communication for children admitted to a specialist children's hospital in the Republic of Ireland. Journal of Clinical Nursing, 17, 3092-3102. doi: 10.1111/j.1365-2702.2008.024262.x

Lambert, V., Glacken, M., \& McCarron, M. (2010). Communication between children and health professionals in a child hospital setting: A Child Transitional Communication Model. Journal of Advanced Nursing, 67(3), 569-582.

Lincoln, Y. \& Guba, E. (1985). Naturalistic inquiry. Newbury Park, CA: Sage Publications.

Livesley, J. \& Long, T. (2013). Children's experiences as hospital in-patients: Voice, competence and work. Messages for nursing from a critical ethnographic study. International Journal of Nursing Studies, 50, 1292-1303.

Marecek, J. (2003). Dancing through mindfields: Toward of a qualitative stance in psychology. In P.M. Camic, J.E. Rhodes, \& L. Yardley (Eds.), Qualitative research in psychology: Expanding perspectives in methodology and design (pp.49-63) Washington, DC: APA.

Marecek, J., Fine, M., \& Kidder, L. (1997). Working between worlds: Qualitative methods and social psychology. Journal of Social Issues, 53(4), 631-644. doi:10.1111/j.1540-4560.1997.tb02452.x

Miles, L. (2009). Who is approachable? Journal of Experimental Social Psychology, 45, 262-266. doi:10.1016/j.jesp.2008.08.010

Morse, J. M. (2011). What is qualitative health research? In N. S. Denzin, \& Y. S. Lincoln (Eds.), The SAGE handbook of qualitative research, (4th ed., pp. 401-414). Los Angeles, CA: Sage.

Newman, B., \& Newman, P. (2012). Development through life: A psychosocial approach (11th ed.). Belmont, CA: Wadsworth Cengage Learning.

Parse, R. R. (2001). The qualitative descriptive method. In Qualitative inquiry: The 
path of sciencing (pp. 57-60). Sudbury, MA: Jones \& Bartlett.

Pelander, T., Leino-Kilpi, H., \& Katajisto, J. (2007). Quality of pediatric nursing care in Finland - Children's perspective. Journal of Nursing Care Quality, 22(2), 185-194. doi:1.1171.19

Pena, A. \& Juan, L. (2011). The experience of hospitalized children regarding their interactions with nursing professionals. Revista Latino-Americana de Enfermagem, 19(6): 1429-36.

Polit, D. F., \& Beck, C.T. (2008). Enhancing quality and integrity in qualitative research. In Nursing research: Generating and assessing evidence for nursing practice (8th ed., pp. 536-555). Philadelphia, PA: Wolters Kluwer/Lippincott Williams \& Wilkins.

Polit, D., \& Beck, C. (2012). Nursing research: Generating and assessing evidence for nursing practice. Philadelphia: Lippincott, Williams \& Wilkins.

Risjord, M. (2009). Rethinking concept analysis. Journal of Advanced Nursing, 65(3), 684-691.

Rollins, J. (2005). Tell me about it: Drawing as a communication tool for children with cancer. Journal of Pediatric Oncology Nursing, 22(4), 203-221. doi: $10.1177 / 1043454205277103$

Rubin, J. (1984). Child art therapy: Understanding and helping children grow through art ( $2^{\text {nd }}$ ed.). New York: Van Nostrand Reinhold.

Sandelowski, M. (2000). Whatever happened to qualitative description? Research in Nursing and Health, 23, 334-340.

Sandelowski, M (2010). What's in a name? Qualitative description revisited. Research in Nursing and Health, 33, 77-84.

Schin, H. \& White-Traut, R. (2005). Nurse-child interaction on an inpatient paediatric unit. Journal of Advanced Nursing, 52(1), 56-62.

Schreier, M. (2012). Qualitative content analysis in practice. Los Angeles, CA: Sage.

Schwartz-Barcott, D. \& Kim, S. (2000). An expansion and elaboration of the hybrid model of concept development. In Rodgers, B.L. \& K. A. Knafl (Eds.). Concept development in nursing: Foundation, techniques and applications. (2nd ed.). Philadelphia: W.B. Sanders, 129-159.

Seidman, I. (2013). Interviewing as qualitative research: A guide for researchers in education and social sciences (4th ed.). New York: Teachers College Press. 
Shattell, M. (2004). Nurse-patient interaction: A review of the literature. Journal of Clinical Nursing, 13, 714-722.

Soderback, M., Coyne, I. \& Harder, M. (2011). The importance of including both a child perspective and the child's perspective within healthcare settings to provide truly child-centered care. Journal of Child Health Care, 15(2), 99-106. doi: $10.1177 / 136749351039764$

St. Jude Children's Research Hospital. (2017). Childhood cancer facts. Retrieved from https://www.stjude.org/treatment/pediatric-oncology/childhood-cancer$\underline{\text { facts.html }}$

Streubert, H. J., \& Carpenter, D. R. (2007). The conduct of qualitative research: Common essential elements. In Qualitative research in nursing: Advancing the humanistic imperative (5th ed., pp. 18-33). Philadelphia, PA: Lippincott, Williams \& Wilkins.

Taylor, C., Lillis, C., LeMone, P., \& Lynn, P. (2015). Fundamentals of nursing: The art and science of nursing care. ( ${ }^{\text {th }} \mathrm{Ed}$.). Philadelphia, PA: Lippincott, Williams, \& Wilkins.

Ward, E., DeSantis, C., Robbins, A., Kohler, B., \& Jemal, A. (2014). Childhood and adolescent cancer statistics, 2014. CA: A Cancer Journal for Clinicians, 64(2), 83-103.

Willis, M., Dodd, H., \& Palermo, R. (2013). The relationship between anxiety and the social judgments of approachability and trustworthiness. PLOS ONE, 8(10), e76825. doi: 10.1371/journal.pone.0076825

Willis, M., Palermo, R. \& Burke, D. (2011). Judging approachability on the face of it: The influence of face and body expressions on the perception of approachability. Emotion, 11(3), 514-523. doi:10.1037/a0022571

Wilson, J. (1963). Thinking with concepts. New York: Cambridge University Press.

United Nations Children's Fund, UNICEF. (2003). The state of the world's children. New York and Geneva: UNICEF.

United Nations Convention on the Rights of the Child, UNCRC. (1989a). Convention on the rights of the child. Geneva: United Nations.

United Nations Convention on the Rights of the Child, UNCRC. (1989b). Retrieved from http://www.ohchr.org/en/professionalinterest/pages/crc.aspx

United Nations International Children's Emergency Fund, UNICEF. (n.d.a). UNICEF - The Conventions on the Rights of the Child. Retrieved from 
http://www.unicef.org/rightsite/

United Nations International Children's Emergency Fund, UNICEF. (n.d.b). UNICEF Publications. Retrieved from http://www.unicef.org/publications

UN General Assembly on Children. (2002). Special session of the UN Assembly on children. Retrieved from http://www.unicef.org/specialsession/ 